\title{
EQUILIBRIUM SHORT-RATE MODELS VS NO-ARBITRAGE MODELS: LITERATURE REVIEW AND COMPUTATIONAL EXAMPLES
}

\section{Dushko Josheski}

Business Administration, University Goce Delchev, Stip, Macedonia e-mail: dusko.josevski@ugd.edu.mk

ORCID: 0000-0002-7771-7910

\section{Mico Apostolov}

Business Administration, University Goce Delchev, Stip, Macedonia e-mail: mico.apostolov@ugd.edu.mk

ORCID: 0000-0003-3697-1346

\section{(C) 2021 Dushko Josheski, Mico Apostolov}

This work is licensed under the Creative Commons Attribution-ShareAlike 4.0 International License. To view a copy of this license, visit http://creativecommons.org/licenses/by-sa/4.0/

Quote as: Josheski, D., and Apostolov, M. (2021). Equilibrium short-rate models vs no-arbitrage models: Literature review and computational examples. Econometrics. Ekonometria. Advances in Applied Data Analysis, 25(3).

DOI: 10.15611/eada.2021.3.03

JEL Classification: E43, E47

\begin{abstract}
In this paper equilibrium short-rate models are compared against no-arbitrage short-rate models. This article is composed of the introduction to this literature and a review, followed by numerical examples of one-factor short-rate models; the Cox-Ingersoll-Ross (CIR) model and the Vasicek model. No-arbitrage models were presented through the Hull-White (HW) model, the Binomial lattice model for bond pricing and interest rate modelling, the Black-Karasinski (BK) model, and the Heath-Jarrow-Morton (HJM) model. The results prove that no single interest rate model exists that can be used for all purposes. These models were compared in terms of volatility, mean reversion process and convergence. The end results confirm the dependence of volatility on the level rate as a determinant of the predictive success of these models.
\end{abstract}

Keywords: equilibrium models, one factor short-rate models, no-arbitrage models,Vasicek model, Hull-White (HW) model, Black-Karasinski (BK) model, Heath-Jarrow-Morton (HJM) model, Cox-Ingersoll-Ross (CIR) model. 


\section{Introduction}

Short-rate models are a mathematical model that are used in the evaluation of interest rate derivatives to illustrate the evolution of interest rates over time by determination of the evolution of the short rate $d r(t)$ over time. The free short-term interest rate is a key economic variable, since it affects the short end of the term structure and has implications in the pricing of the full range of fixed income securities and derivatives, see (Andersen and Lund, 1997). In the literature, most of the models for option or discount bond pricing, or at least several of them, are developed in a continuous time framework, with the arithmetic Brownian motion ${ }^{1}$, e.g. (Black and Scholes, 1973; Merton, 1973). Other models such as the Vasicek (1977) model use the Ornstein-Uhlenbeck process ${ }^{2}$ which is a Gauss-Markov process, that over time tends to drift towards its mean function; such a process is termed as mean-reverting, see (Björk, 2009). Mean-reversion is understood here as the change of the market return in the direction of a reversion level as a reaction to a prior change in the market return, see (Hillebrand, 2003). Empirical evidence on "on the extent to which stock prices exhibit mean-reverting behaviour" can be found in (Poterba and Summers, 1988). The two major classes of interest rate models can be described as: "no-arbitrage term structure models" and "short rate models", see also (Cairns (2004; Treepongkaruna and Gray, 2003).The first equilibrium models of short rate were built on the assumption of how the economy works. Equilibrium models or short-rate models such as those developed by Vasicek (1977), Dothan (1978), Cox, Ingersoll, Ross (1980), Cox, Ingersoll, and Ross (CIR) (1985), the Ho-Lee Model (1986) was the first paper that developed this idea prominently. Longstaff (1989, 1992), Longstaff and Schwartz (1992), Brennan and Schwartz (1979, 1982) and Chan, Karolyi, Longstaff, and Sanders (hereafter CKLS) (1992) all started with an stochastic differential equation (SDE) model and developed pricing mechanisms for bonds under an equilibrium framework, in these models drift and diffusion parameters are not allowed to vary over time, see also (Buetow, Fabozzi and Sochacki, 2012). The inverse of the CIR model ${ }^{3}$ is discussed in

${ }^{1}$ Definition of Brownian motion: Let $\left(\mathcal{W}_{t}, \mathcal{F}_{t}\right)_{t \in(0, \infty)}$ be an $\mathbb{R}$-valued continuous stochastic process in probability space $(\Omega, \mathcal{F}, \mathcal{P})$, then $\left(\mathcal{W}_{t}, \mathcal{F}_{t}\right)_{t \in(0, \infty)}$ is called standard Brownian motion if: $\mathcal{W}=0 ; \quad \mathcal{W}_{t}-\mathcal{W}_{s} \sim \mathcal{N}(0, t-s) ; \mathcal{W}_{t}-\mathcal{W}_{s} \perp \mathcal{F}_{s}$. An $\mathbb{R}^{T}$ valued process $\mathbb{W}_{t}$ is called $T$-dimensional Brownian motion with initial value $x \in \mathbb{R}^{T}$ if $\mathbb{W}_{t}=x+\left(W_{t}^{1}, \ldots, W_{t}^{T}\right), \forall t \in(0, \infty)$, where $\mathcal{W}_{t}^{i}$ are standard Brownian motions, see (Ewald, 2007).

${ }^{2}$ Suppose $x_{1},(t), x_{2}(t), \ldots x_{d}(t)$ are $d$ dependent Ornstein-Uhlenbeck processes where $d x_{i}(t)=$ $-\frac{1}{2} \alpha x_{i}(t) d t+\sqrt{\alpha} d B_{i}(t)$, where $B_{i}(t)$ are standard Brownian motions, $\sqrt{\alpha}$ represents volatility and $-\frac{1}{2} \alpha$ is a mean-reversion rate. Here $x(t)$ follows normal distribution with $\left(x_{i}(0) e^{-\frac{\alpha t}{2}} ; 1-e^{-\alpha t}\right)$. The squared radius of the vector $x(t)$ is $R(t)=\sum_{i=1}^{d} x_{i}(t)^{2} \rightarrow d R(t)=\sum_{i=1}^{d}\left(2 x_{i}(t) d x_{i}(t)+\right.$ $\left.d\left(x_{i}\right)(t)\right)=\alpha(d-R(t)) d t+\sqrt{4 \alpha} d \widetilde{W}_{l}(t) ; \theta=\frac{4 \alpha}{\sigma^{2}}$ and $d=\frac{4 \alpha \mu}{\sigma^{2}}$ and we have that $r(t)=\frac{R(t)}{\theta}$.

${ }^{3}$ Inverse of the CIR model is given as: $d r=r\left\{k\left(\sigma^{2}-k \alpha\right) r\right\} d t+\sigma^{\frac{3}{2}} d B$, while the CIR model 1985 is given as: $d r=\alpha(\beta-r) d t+\sigma r^{\frac{1}{2}}$, where $k$ in the first expression is a mean-reversion. 
(Ahn and Gao, 1999) and then (Aït-Sahalia, 1999). No-arbitrage models (no-arbitrage bounds represent mathematical relations that are specifying limits on portfolio prices. These price bounds are a specific example of good-deal bound, see (Birge, 2008)). The general approach to option pricing is first to assume that prices do not provide arbitrage opportunities. For a more general explanation on good-deal bounds see Björk, Tomas, Slinko, Irina. (2006). Black and Karasinski, (1991), Black, Derman, and Toy (1990) ${ }^{4}$, Ho and Lee (1986), Heath, Jarrow, and Morton (1992), and Hull and White (1990, 1993 ) begin with the same or similar SDE models as the equilibrium approach, but use market prices to generate an interest rate lattice. No-arbitrage models are the preferred framework to evaluate the value of interest rate derivatives. The derivation of the option prices is obtained by replicating the payoffs provided by the option using the underlying asset and risk-free borrowing/lending. The simplest form of no-arbitrage model is put-call parity to obtain values market prices of bonds that are exact. Equilibrium models will not price bonds exactly. In this paper the authors took into consideration: the Hull-White one factor model to simulate the price of a bond and the total return of a bond portfolio, followed by the CIR model to simulate the daily short rates. The tree models are presented through the Black-Karasinski (BK) model (the (BK) Black-Karasinski model is a single-factor, log-normal version of the HW model), and the Heath-Jarrow-Morton (HJM) model. The (HJM) Heath-Jarrow-Morton model considers a given initial term structure of interest rates and a specification of the volatility of forward rates to build a tree representing the evolution of the interest rates, based on a statistical process (see also MathWorks ${ }^{\circledR}$ help center). These models use sets of zero-coupon bonds ${ }^{5}$ to predict changes in interest rates ${ }^{6}$. This paper compared two types of models and drew conclusions as to which models are best suited to be used (the authors tested their volatility with respect to the level rate, as a determinant of the success of the model).

\section{Fundamental theorem of asset pricing}

Theorem 1. Suppose that bond prices evolve in a way that is stochastic, if $\exists Q \equiv P$, under which for $\forall T$, the discounted price process $\mathcal{P}(t, T) / \mathcal{B}(t)$ is martingale ${ }^{7}$ for all

${ }^{4}$ Empirical investigation of the Black-Derman-Toy model (BDT) (Bali, 1999), uses the data set originally constructed by Fama (1984) and then updated by the Center for Research in Security Prices (CRSP).

${ }^{5}$ Zero-coupon bond prices $P(t, T)$ by definition are related to forward rates: $f(t, T)=-\frac{\partial \log (t, T)}{\partial T}$ $P(T, T)=1 ; P(t, T)=\frac{P(0, T)}{P(0, t)} e^{\beta(t, T)(f(t, 0)-r t)-\frac{1}{2} v(t) \beta 2(t, T)}$, where $\beta(t, T):=\int_{t}^{T} e^{-\int_{t}^{s} k u d u} d s$.

${ }^{6}$ A zero-coupon bond is a bond that, instead of carrying a coupon, is sold at a discount from its face value, pays no interest during its life, and pays the principal only at maturity.

${ }^{7}$ Martingale is a sequence of variables: $x_{0}, x_{1}, \ldots$. With finite means such that the conditional expectation of $x_{n+1}$ is given as: $\left(x_{n+1} \mid x_{0}, \ldots, x_{n}\right)=x_{n}$. One dimensional random walk is an example of martingale, see (Doob, 1953). 
$\forall t: 0<t<T$. If this holds then the market is complete if and only if $\mathcal{Q}$ is a unique measure under which $\mathcal{P}(t, T) / \mathcal{B}(t)$ are martingales.

In the previous theorem: $\mathcal{B}(t)=\mathcal{B}(0) \exp \left(\int_{0}^{t} r(s) d s\right)$ is a cash account numeraire, $(\Omega, \mathcal{F}, \mathcal{P})$, is a probability space (sample space, event space, and probability function) see Stroock (1999), $\mathcal{Q}$ is an equivalent martingale measure or risk neutral measure, see Cairns 2004).

$$
\begin{gathered}
\text { Corollary } 1 \text { First } \mathcal{P}(t, T)=E_{Q}\left[\exp \left(-\int_{t}^{T} r(s) d s\right) \mid \mathcal{F}_{t}\right]= \\
E_{\mathcal{Q}}\left[\exp \left(-\int_{s=t}^{T-1} r(s)\right) \mid \mathcal{F}_{t}\right] .
\end{gathered}
$$

Where $\mathcal{F}_{t}$ is a $\sigma$ algebra ${ }^{8}$ generated by the price histories up to the time, $E_{Q}$ implies expectations with respect to the equivalent martingale measure. Fair value $\mathcal{V}(t)$ at time $t$ under $x$ which is some $\mathcal{F}_{t}$ measurable derivative payment payable, then the discounted price process $\frac{\mathcal{V}(t)}{\mathcal{B}(v)}$ is also martingale under $\mathcal{Q}$ so $\mathcal{V}(t, T)=$ $E_{Q}\left[\exp \left(-\int_{t}^{T} r(u) d u\right) x \mid \mathcal{F}_{t}\right]$.

Proof: $r_{t} \in \mathcal{A}$ where $\mathcal{A}=\left\{r_{-1} ; r_{0}, r_{1}, r_{2}\right\}$, where $\mathcal{P}_{t, t+2}=P_{r}\left[r_{i+1} \mid r_{t}\right]=1$, also $\mathcal{P}\left(t, t+2, r_{i}\right)=e^{-\left(r_{i}\right)}\left[q_{i} e^{-r_{i}}+\left(1-q_{i}\right) e^{-r_{i-1}}\right] ; 0<q_{i}<1$. Now let $Z(t, T)=$ $\mathcal{P}(t . T) / \mathcal{B}(t, T)$. Where $\mathcal{D}(t, T)=E_{\mathcal{Q}}\left[\frac{1}{\mathcal{B}(T)} \mid \mathcal{F}_{t}\right]$. Where $\mathcal{D}$ is a martingale under $\mathcal{Q}$ by the law of total conditional expectation. Now

$$
\begin{gathered}
\mathcal{Z}(t, t+2)=\frac{\mathcal{P}_{t, t+2}}{\mathcal{B}(t)}=\exp \left(-\int_{s=t}^{T-1} r(s)\right) e^{-\left(r_{t}\right)} E_{\mathcal{Q}}\left[\mathcal{P}(t+1, t+2) \mid \mathcal{F}_{t}\right] \\
=E_{Q}\left[Z(t+1, t+2) \mid \mathcal{F}_{t}\right] .
\end{gathered}
$$

$\mathcal{Z}(t, t+2)$ is martingale under $\mathcal{Q}$ from $t \rightarrow t+1$, by the martingale Representation theorem $\exists \phi(t, T)$ which is a predictable process such that: $\mathcal{D}(t, T)=\mathcal{D}(0, T)+\sum_{s=1}^{t} \phi(s, T) \Delta Z(s, s+1)$. Now let $\psi(t, T)=\mathcal{D}(t-1, T)-$ $\phi(t, T) Z(t-1, t+1)$. The value of this portfolio which holds $\phi(t, T)$ units of bonds that matures at $t+1, \mathcal{P}(t-1, t+1)$ plus $\psi(t, T)$ units of risk free bonds, $\mathcal{B}_{t-1} \rightarrow \mathcal{B}_{t}$. The value of portfolio at time $t$ after rebalancing is:

$$
\begin{aligned}
\mathcal{V}(t, T)=\phi( & +1, T) \mathcal{P}(t, t+2)+\psi(t+1, T) \mathcal{B}(t) \\
& =\mathcal{B}[\phi(t+1, T) \mathcal{Z}(t, t+2) \psi(t+1, T)=\mathcal{B}(t) \mathcal{D}(t, T) \\
& =\mathcal{B}[\phi(t, T) \mathcal{Z}(t, t+1) \psi(t, T) \\
& =\phi(t, T) \mathcal{P}(t, t+1)+\psi(t, T) \mathcal{B}(t) .
\end{aligned}
$$

${ }^{8}$ Let $\mathcal{P}(x)$ is a $\mathcal{P}(s)$, then a subset $\sum \subseteq \mathcal{P}(x)$ is $\sigma$-algebra if it satisfies: $x \in \sum$, and is considered to be $U$, and if $x \in \sum \Rightarrow \bar{x} \in \sum$; and if $x_{1}, x_{2}, \ldots \in \sum$ then $x=x_{1} \cup x_{2} \ldots$ see (Rudin, 1987). 
Since by the law of one price i.e. no-arbitrage $\mathcal{V}(T, T)=\mathcal{B}(T) \mathcal{D}(T, T)$ further one can state that $\mathcal{P}(t, T)=e^{-r_{t}} E_{\mathcal{Q}}\left[\exp \left(-\int_{s=t}^{T-1} r(s)\right) \mid r_{t}\right]=e^{-r_{t}} E_{Q}$ $\left[\mathcal{P}(t+1, T) \mid r_{t}\right]$ and the relevant $\mathcal{Q}$ probabilities are given in the theorem $\mathbf{a}$.

\section{The Vasicek model}

The Vasicek model (1977) is a one-factor short-rate model, that describes interest rate movements driven by only one factor of market risk. Vasicek (1977) proposed the following model:

$$
d r(t)=\alpha(\mu-r) d t+\sigma d \widetilde{W}(t),
$$

where $\mu$ is a risk-free interest rate; $\alpha$ represents a rate at which $r(t)$ reverts to the long-term mean; $\sigma$ represents volatility of short-term interest rates; $\widetilde{W}(t)$ is the standard Brownian movement under risk neutral measure $\mathcal{Q}$, and $\mu>0 ; \sigma>0 ; s>0$, $r(t+s)$ given $r(t)$ is normally distributed under risk-neutral measure $\mathcal{Q}$ with mean and $\operatorname{var} .\left(\mu+(r(t)-\mu) e^{\alpha s} ; \frac{\sigma^{2}\left[1-e^{-2 \alpha s}\right]}{2 \alpha}\right)$.

Theorem 2. Under the Vasicek model prices of bonds are given as:

$$
\mathcal{P}(t, T)=\exp [\mathcal{A}(t, T)-\mathcal{B}(t, T) r(t)],
$$

where: $\mathcal{B}=\frac{1-e^{-\alpha(T-t)}}{\alpha} \mathcal{A}(t, T)=(\mathcal{B}(t, T)-(T-t))\left(\mu-\frac{\sigma^{2}}{2 \alpha^{2}}\right)-\frac{\sigma^{2}}{4 \alpha} \mathcal{B}(t, T)^{2}$.

Lemma 1: Laplace transform for $\int_{t}^{T} r(s) d s$ for given $r(t) ; r(T)$ is:

$$
\begin{gathered}
\mathcal{P}_{L}=(t, T, r, v, \omega)=E_{Q}\left[\exp \left(-v \int_{t}^{T} r(s) d s-\omega r(T) \mid r(t)\right]\right. \\
=\exp [\mathcal{A}(t, T, v, \omega)-\mathcal{B}(t, T, v, \omega)]
\end{gathered}
$$

where $=T-t, \mathcal{B}(t, T, v, \omega)=v \mathcal{B}_{1}(t, T)+\omega \mathcal{B}_{2}(t, T)$, where $\mathcal{B}_{1}(t, T)=\frac{1-e^{-\alpha t}}{\alpha}$ and $\mathcal{B}_{2}(t, T)=e^{-\alpha t}$. Also, $\mathcal{A}(t, T, v, \omega)=-v \mathcal{A}_{1}(t, T)-\omega \mathcal{A}_{2}(t, T)+\frac{1}{2} v^{2} \mathcal{C}_{11}(t, T)$ $+v \omega^{2} \mathcal{C}_{22}(t, T)$, where $\quad \mathcal{A}_{1}(t, T)=\mu\left(\tau-\frac{1-e^{-\alpha \tau}}{\alpha}\right) ; \mathcal{A}_{2}(t, T)=\mu\left(1-e^{-\alpha t}\right)$. Also, $\mathcal{C}_{11}(t, T)=\frac{\sigma^{2}}{2 \alpha^{3}}\left(1-e^{-\alpha t}\right)^{2} ; \mathcal{C}_{22}(t, T)=\frac{\sigma^{2}}{2 \alpha^{3}}\left(1-e^{-\alpha t}\right)$. From previous $\int_{t}^{T} r(s) d s$ have a bivariate normal distribution under: $E_{Q}[r(t) \mid r(T)]=$ $\mathcal{B}_{2}(t, T) r(t)+\mathcal{A}_{2}(t, T)=\mu+(r(t)-\mu) e^{-\alpha t} \quad$ and $\quad E_{Q}\left[\int_{t}^{T} r(s) d s \mid r(t)\right]=$ $\mathcal{B}_{1}(t, T) r(t)+\mathcal{A}_{1}(t, T)=\mu \tau+(r(t)-\mu) \frac{1-e^{-\alpha \tau}}{\alpha}$. Variances are given as: $\operatorname{Var}_{Q}[r(t) \mid r(T)]=\mathcal{C}_{22}(t, T)=\sigma^{2} \frac{1-e^{-2 \alpha \tau}}{\alpha} ; \quad$ and $\quad \operatorname{Var}_{Q}\left[\int_{t}^{T} r(s) d s \mid r(t)\right]=$ 
$\mathcal{C}_{11}(t, T)=\frac{\sigma^{2}}{2 \alpha^{3}}\left[2 \alpha \tau-3+4 e^{-\alpha \tau}-e^{-2 \alpha \tau}\right]$. This lemma can be proven by the Feynman-Kac formula ${ }^{9}$ to see that: $\mathcal{P}_{L}=(t, T, r, v, \omega)$ satisfies PDE:

$$
\frac{\partial \mathcal{P}_{L}}{\partial t}+\alpha(\mu-r) \frac{\partial \mathcal{P}_{L}}{\partial r}+\frac{1}{2} \sigma^{2} \frac{\partial^{2} \mathcal{P}_{L}}{\partial r^{2}}-v r \mathcal{P}_{L}=0
$$

s.t. $\mathcal{P}_{L}=(t, T, r, v, \omega)=\exp (-\omega r)$. The bivariate normality follows when one observes that the $\log \mathcal{P}_{L}=(t, T, r, v, \omega)$ is quadratic in $v ; \omega$.

The price at time $t$ for given $r(t)=r$ of a zero-coupon bond maturing at $T$ is:

$$
\mathcal{P}=(t, T, r)=E_{Q}\left[\exp \left(-\int_{t}^{T} r(s) d s \mid r(t)\right]=\exp [\mathcal{A}(t, T)-\mathcal{B}(t, T) r],\right.
$$

where in the previous expression: $\mathcal{B}_{1}(t, T)=\frac{1-e^{-\alpha t}}{\alpha}$ and $\mathcal{A}(t, T)=-\mathcal{A}_{1}(t, T)+$ $\frac{1}{2} \mathcal{C}_{11}(t, T)=\left(\mu-\frac{\sigma^{2}}{2 \alpha^{2}}\right)(\mathcal{B}(t, T)-(T-t))-\frac{\sigma^{2}}{4 \alpha} \mathcal{B}(t, T)^{2}$, s.t. boundary condition $\mathcal{P}=(t, T, r)=1 \forall r$

\section{The Cox-Ingersoll-Ross (CIR) model (1985)}

In the Cox-Ingersoll-Ross model (1985), the short-rate is assumed to satisfy the following differential equation:

$$
d r(t)=k(\theta-r(t)) d t+\sigma \sqrt{r t} d w(t)
$$

where $k, \sigma, \theta>0$ with $2 k \theta>\sigma^{2}$ and $w$ is a Brownian motion under risk-free measure. Now, let $0 \leq s \leq t \leq T$, the short rate in the CIR model satisfies:

$$
\mathbb{E}(r(t) \mid \mathcal{F}(s))=r(s) e^{-k(t-s)}+\theta\left(1-e^{-k(t-s)}\right)
$$

and also:

$$
\mathbb{V}(r(t) \mid \mathcal{F}(s))=\frac{\sigma^{2} r(s)}{k}\left(e^{-k(t-s)}-e^{-2 k(t-s)}\right)+\frac{\sigma^{2} \theta}{2 k}\left(1-e^{-k(t-s)}\right)^{2} .
$$

In the CIR model, the price of a zero-coupon bond with maturity $T$ at the time $t \in[0, T] \quad$ is given as: $P(t, T)=A(t, T) e^{-r(t) B(t, T)}$, where: $A(t, T)=$

${ }^{9}$ Feynman-Kac formula - Suppose $\exists \mathcal{P}(t, x)$ that satisfies: $\frac{\partial \mathcal{P}}{\partial t}+f(t, x) \frac{\partial \mathcal{P}}{\partial x}+\frac{1}{2} \rho^{2}(t, x) \frac{\partial^{2} \mathcal{P}}{\partial x^{2}}-$ $R(x) \mathcal{P}+h(t, x)=0$ s.t $\mathcal{P}(t, x)=\psi(x)$. Then $\exists \widetilde{W}(t)$ and a measure $\mathcal{Q}$ where the solution is given as $\mathcal{P}(t, x)=E_{Q}\left[\int_{t}^{T} \mathcal{V}(t, u) h(u, x(u)) d u+\mathcal{V}(t, T) \psi(x(t)) \mid \mathcal{F}_{t}\right] ; t<T d x(t)=f(t, x(t)) d t+$ $\rho(t, x(t)) d \widetilde{W}(t) ; \mathcal{V}(t, u)=\exp \left(-\int_{t}^{u} R(x(s) d s)\right.$ given that $\int_{t}^{T} E_{\mathcal{Q}}\left[\left(\rho(s, x(s)) \frac{\partial \mathcal{P}}{\partial x}(s, x(s))\right]^{2} \mid \mathcal{F}_{t}\right]$. 
$\left(\frac{2 h e^{\frac{(h+k)(T-t)}{2}}}{2 h+(h+k)\left(e^{h(T-t)}-1\right)}\right)^{\frac{2 k \theta}{\sigma^{2}}}$ and: $B(t, T)=\frac{2\left(e^{h(T-t)}-1\right)}{2 h+(h+k)\left(e^{h(T-t)}-1\right)}$, here: $h=\sqrt{k^{2}+2 \sigma^{2}}$.

Bond price dynamics in the CIR model is given as: $d P(t, T)=r(t) P(t, T) d t-$ $\sigma \sqrt{r t} B(t, T) P(t, T) d w(t)$. And:

$$
d \frac{1}{P(t, T)}=\frac{\left(\sigma^{2} B^{2}(t, T)-1\right) r(t)}{P(t, T)} d t+\frac{\sigma \sqrt{r t} B(t, T)}{P(t, T)} d w(t) .
$$

Under $T$-forward measure ${ }^{10} \mathbb{Q}^{T}$, the short rate $r$ in the CIR model satisfies: $d r(t)=$ $\left[k \theta+\left(k+\sigma^{2} B(t, T) r(t)\right]+\sigma \sqrt{r(t)} d w^{T}(t)\right.$. In the CIR model the instantaneous forward rate with maturity $T$ is given as: $f(t, T)=k \theta B(t, T)+r(t)+B_{T}(t, T)$, and satisfies the following stochastic differential equation ${ }^{11}: d f(t, T)=$ $\sigma \sqrt{r(t)} B_{T}(t, T) d w^{T}(t)$. Extensions of the models were provided most notably in (Maghsoodi, 1996). There coefficients were replaced with time-varying functions in order to make it consistent with a pre-assigned term structure of interest rates and possibly volatilities, while one extension is given in Chen (1996), which is a three-factor model. The unique solution to $d r(t)=k(\theta-r(t)) d t+\sigma \sqrt{r t} d w(t)$ is given as:

$$
r_{t}=r_{s}+\int_{s}^{t} k\left(\theta-r_{u}\right) d u+\sigma \int_{s}^{t} \sqrt{r(u)} d \mathcal{W}(u) ; s<t .
$$

Hence: $E\left(r_{t} \mid r_{s}\right)=r_{s}+\int_{s}^{t} k\left(\theta-E\left[r_{t} \mid r_{s}\right]\right) d u, s<t$.

Theorem 2. The Laplace transform for the joint random variables $\left(\int_{t}^{T} r(s) d s, r(T)\right)$ given $r(t)$ is: $\mathcal{P}_{l}(t, T, r, v, \omega)=E_{Q}\left[\exp \left(-v \int_{t}^{T} r(s) d s-\omega r t(T)\right) \mid r(t)=r\right]$, where $\mathcal{P}_{l}=\exp [\mathcal{A}(t, T, \omega, v)-\mathcal{B}(t, T, \omega, v) r]$, where:

$$
\begin{gathered}
\mathcal{A}(t, T, \omega, v)=\frac{2 k \theta}{\sigma^{2}} \log \left(\frac{2 \gamma(v) e^{(\gamma(v)+k)\left(\frac{\tau}{2}\right)}}{\left(\sigma^{2} \omega+\gamma(v)+k\right)\left(e^{\gamma(v)(T-t)}+2 \gamma(v)\right.}\right) ; \gamma(v)=\sqrt{k^{2}+2 \sigma^{2} v}, \\
\mathcal{B}(t, T, \omega, v)=\frac{\omega\left(2 \gamma(v)+(\gamma(v)-k)\left(e^{\gamma(v)(T-t)}-1\right)+2 v\left(e^{\gamma(v)(T-t)}-1\right)\right.}{\left(\sigma^{2} \omega+\gamma(v)+k\right)\left(e^{\gamma(v)(T-t)}+2 \gamma(v)\right.} .
\end{gathered}
$$

${ }^{10}$ Where $\mathbb{Q}^{T}$ Brownian motion is defined as: $d w^{T}(t)=d w(t)+\sigma B(t, T) \sqrt{r(t)} d t$.

${ }^{11}$ Forward rate dynamic in the CIR model is given as: $d F(t, T, S)=\sigma\left(F(t, T, S)+\frac{1}{\tau(T, s)}\right) \times$ $\sqrt{(B(t, S)-B(t, T)) \ln \left((\tau(T, S) F(t, T, S)+1) \frac{A(t, S)}{A(t, T)}\right.} d w^{S}(t)$. 
For zero-coupon bonds by taking $v=1 ; \omega=0$, and we have $\mathcal{P}_{l}(t, T, r)=$ $\exp [\overline{\mathcal{A}}(T-t)-\overline{\mathcal{B}}(T-t) r], \quad$ where: $\overline{\mathcal{A}}(\tau)=\frac{2 k \theta}{\sigma^{2}} \log \left(\frac{2 \gamma e^{(\gamma+k)\left(\frac{\tau}{2}\right)}}{\left(\sigma^{2} \omega+\gamma+k\right)\left(e^{\gamma(T-t)}+2 \gamma\right.}\right) ;$ $\gamma(v)=\sqrt{k^{2}+2 \sigma^{2}}$ and also $\overline{\mathcal{B}}(\tau)=\frac{2\left(e^{\gamma \tau}-1\right)}{(\gamma+k)\left(e^{\gamma \tau}-1\right)+2 \gamma}$.

Proof: For the first part of the proof, let us recall that:

$\mathcal{P}_{l}(t, T, r, v, \omega)=E_{Q}\left[e^{-v \int_{t}^{T} r(s) d s-\omega r(T)} \mid r(t)=r\right] ; d r(t)=k(\theta-r(t)) d t+$ $\sigma \sqrt{r t} d w(t)$, one can apply the converse of the Feynman-Kac formula to see that $\mathcal{P}_{l}(t, T, r, v, \omega)$ must satisfy the following PDE: $\frac{\partial \mathcal{P}_{l}}{\partial t}+k(\theta-r) \frac{\partial \mathcal{P}_{l}}{\partial r}+\frac{1}{2} \sigma^{2} r \frac{\partial^{2} \mathcal{P}_{l}}{\partial r^{2}}-$ $\operatorname{vr} \mathcal{P}_{l}=0$, s.t. boundary condition $\mathcal{P}_{l}(t, T, r, v, \omega)=e^{-\omega r}$. For the zero-coupon bonds prices: $\mathcal{P}(t, T, r)=E_{Q}\left[e^{-\int_{t}^{T} r(s) d s} \mid r(t)=r\right]=\mathcal{P}_{l}(t, T, r, 1,0)$, substitutiong $v=1 ; \omega=0$ one obtains the previous expression $\mathcal{P}_{l}(t, T, r)=\exp [\overline{\mathcal{A}}(T-t)-$ $\overline{\mathcal{B}}(T-t) r]$

\section{The Hull-White model (1990)}

Hull and White (1990) explored extensions of the Vasicek model (1977) that provide an exact fit to the initial term structure ${ }^{12}$. One version of the extended Vasicek model that they considered was:

$$
d r_{t}=\left[\theta(t)-a r_{t}\right] d t+\sigma d \mathcal{B}_{t}
$$

and $r=a\left[\frac{\theta(t)}{a}-r_{t}\right] d t+\sigma d \mathcal{B}_{t}$, where $r$ is short-term interest rate and $a, \sigma$ are positive constants. $\theta(t)$ is a function of time chosen to ensure that the model fits the initial term structure. The variable $\theta(t)$ defines the average direction that $r$ moves at time $t$, and $\mathcal{B}_{t}$ is a Brownian motion. A continuous-time stochastic process $w(t)$ for $t \geq 0$ with $w(0)=0$ and such that the increment $w(t)-w(s)$ is Gaussian with mean 0 and variance $t-s$ for any $0 \leq s \leq t$, and increments for nonoverlapping time intervals are independent. Brownian motion (i.e. random walk with random step sizes) is the most common example of a Wiener process. When $a=0$, the Hull-White model becomes its alternative Ho-Lee model (1986):

12 Hull and White (1990) provided simple framework of the Vasicek model: $d r(t)=$ $\alpha(\mu(t)-r(t)) d t+\sigma d \widetilde{\mathcal{W}}(t)$, in order for the theoretical and observed prices to match the condition required are: $\mu(t)=\frac{1}{\alpha} \frac{\partial}{\partial t} f(0, t)+f(0, t)+\frac{\sigma^{2}}{2 \alpha^{2}}\left(1-e^{-2 \alpha t}\right) ; \mathcal{P}(t, T)=\exp [\mathcal{A}(t, T)-\mathcal{B}(t, T) r(t)]$, where $\mathcal{A}(t)=\log \frac{\mathcal{P}(0, T)}{\mathcal{P}(0, t)}+\mathcal{B}(t, T) f(0, t)-\frac{\sigma^{2}}{4 \alpha^{3}}\left(1-e^{-\alpha(\mathrm{T}-t)}\right)^{2}\left(1-e^{-2 \alpha t}\right) ; \mathcal{B}(t, T)=\frac{1-e^{-\alpha(\mathrm{T}-t)}}{\alpha}$.

The Ornstein-Uhlenbeck process provides the following: $r(t)=e^{\alpha t} r(0)+\alpha \int_{0}^{t} e^{-\alpha(t-s)} \mu(s) d s+$ $\sigma \int_{0}^{t} e^{-\alpha(t-s)} d \widetilde{\mathcal{W}}_{s}$ 


$$
d r=\theta(t) d t+\sigma d w .
$$

Function $\theta(t)$ can be calculated from the initial term structure: $\theta(t)=F_{t}(0, t)+$ $a F(0, t)+\frac{\sigma^{2}}{2 a}\left(1-e^{-2 a t}\right)$. The last term of the equation is small so if ignored it: $F_{t}(0, t)+a[F(0, t)-r]$. This shows that, on average, $r$ follows the slope of the initial instantaneous forward rate curve. When it deviates from that curve, it reverts back to it at rate $a$. Or, when a current term structure is matched, Hull and White (1993): $\theta(t)=\frac{\partial f(0, t)}{\partial t}+a f(0, t)+\frac{\sigma^{2}}{2 a}\left(1-e^{-2 a t}\right)$. It turns out that the time-s value of the T-maturity discount bond has distribution, see (Hull and White, 1996):

$$
P(s, T)=\mathcal{A}(s, T)=\mathcal{A}(s, T) \cdot e^{B(s, T), r(s)},
$$

where $\mathcal{B}(s, T)=\frac{1-e^{-a(T-s)}}{a}$ and $\quad \ln \mathcal{A}(s, T)=\ln \frac{P(0, T)}{P(0, s)}-\mathcal{B}(s, T) \cdot \frac{\partial \ln P(0, s)}{\partial s}-\frac{1}{4 a^{3}}$ $\sigma^{2}\left(e^{-a T}-e^{-a s}\right)\left(e^{2 a t}-1\right)$. These equations define the price of a zero-coupon bond at a future time $t$ in terms of the short rate at time $t$ and the prices of bonds today. The latter can be calculated from today's term structure. $P(s, T)$ is log-normally distributed. The solution for $\theta$ here is given as in (Gurrieri, Nakabayashi, and Wong, 2009):

Proposition 1. The proposed solution to the model is given as: $\theta(t)=\frac{\partial}{\partial t} f(0, t)+$ $\alpha(t) f(0, t)+\frac{1}{2}\left(\frac{\partial^{2}}{\partial t^{2}} \mathcal{V}(0, t)+\alpha(t) \frac{\partial}{\partial t} V(0, t)\right)$, where $f(0, t)$ is the instantaneous forward rate at time $t, \mathcal{V}(t)=\int_{t}^{T} \sigma^{2}(t, T) d t, \sigma(t, T)=\sigma(t) \mathcal{B}(t, T)$.

Proof: The assumption here is that $\{r(t), t \geq 0\}$ satisfies SDE $d r_{t}=$ $\left[\theta(t)-a(t) r_{t}\right] d t+\sigma d w_{t}, t>0$, where $\left\{w_{t}, t \geq 0\right\}$ is a standard Brownian motion. First, one notes that:

$$
\begin{aligned}
d\left(e^{\int_{0}^{t} \alpha(t) d t} r(t)\right) & =\alpha(t) e^{\int_{0}^{t} \alpha(t) d t} r(t) d t+e^{\int_{0}^{t} \alpha(t) d t} d r(t) \\
= & \theta(t) e^{\int_{0}^{t} \alpha(t) d t} d t+\sigma(t) e^{\int_{0}^{t} \alpha(t) d t} d \mathcal{B}_{t}
\end{aligned}
$$

Then for $t_{1}>t$ we have: $r\left(t_{1}\right)=r(t) e^{-\int_{t}^{t_{1}} \alpha(t) d t}+\int_{t}^{t_{1}} \theta(s) e^{-\int_{s}^{t_{1}} \alpha(t) d t}+$ $\int_{t}^{t_{1}} \sigma(s) e^{-\int_{s}^{t_{1}} \alpha(t) d t} d \mathcal{B}_{s}$, also for $0 \leq t \leq T$ we have that $^{13} \mathcal{P}(t, T)=$ $E\left(e^{\int_{t}^{T} r_{s} d s} \mid \mathcal{F}_{t}\right)$. From the previous one can write:

${ }^{13}$ Here $\mathcal{F}_{t}$ is the information set or price history as defined before. The probability law in the Markov models requires prices as input and the probability law of $\mathcal{P}(s, T) \mid \mathcal{F}_{t}$, where $t<s<T$ which is equal to that of $\mathcal{P}(s, t) \mid x(t)$ in some finite dimensional Ito process. $\mathcal{W}_{t}$ is also a Markov process, that is the law of $\{\mathcal{W}(u): u \geq t\}$ for a given $\mathcal{F}_{t}$ is the same law of $\{\mathcal{W}(u): u \geq t\}$ for a given $\mathcal{W}_{t}$ only. $\mathcal{W}_{t}$ is a martingale for $s>t \quad E\left[\mathcal{W}(s) \mid \mathcal{F}_{t}\right]=\mathcal{W}_{t}$. Also a stochastic process $x(t)=x(0)+$ $\int_{0}^{t} a(u) d u+\int_{0}^{t} b(u) d \mathcal{W}(u)$ where $a(u)$ and $b(u)$ are $\mathcal{F}_{t}$-adapted processes and $\int_{0}^{t} b(u) d \mathcal{W}(u)$ is the 


$$
\begin{gathered}
\mathcal{P}(t, T)=E\left(e^{\int_{t}^{T} r_{s} d s} \mid \mathcal{F}_{t}\right)= \\
e^{-r(t) \mathcal{B}(t, T)} E\left(e^{-\int_{t}^{T} \theta(s) \mathcal{B}(s, T) d s-\int_{t}^{T} \theta(t) \mathcal{B}(s, T) d \mathcal{B}_{s}} \mid \mathcal{F}_{t}\right)= \\
e^{-r(t) \mathcal{B}(t, T)-\int_{t}^{T} \theta(s) \mathcal{B}(s, T) d s+\frac{1}{2} \mathcal{V}(t, T)}
\end{gathered}
$$

Furthermore, $f(0, t)=-\frac{\partial}{\partial t} \ln \mathcal{P}(0, t)=r(0) e^{-\int_{0}^{t} \alpha(t) d t}+\int_{0}^{t} \theta(s) e^{-\int_{s}^{t_{1}} \alpha(t) d t}$ $d s-\frac{1}{2} \frac{\partial}{\partial t} \mathcal{V}(0, t)$ and $\frac{\partial}{\partial t} f(0, t)=-\alpha(t)\left(f(0, t)+\frac{1}{2} \frac{\partial}{\partial t} \mathcal{V}(0, t)\right)+\theta(t)-\frac{1}{2} \frac{\partial^{2}}{\partial t^{2}}$. If rearranged one obtains to $\theta(t)=\frac{\partial}{\partial t} f(0, t)+\alpha(t) f(0, t)+\frac{1}{2}\left(\frac{\partial^{2}}{\partial t^{2}} \mathcal{V}(0, t)+\right.$ $\left.\alpha(t) \frac{\partial}{\partial t} V(0, t)\right)$

\section{The Black-Karasinski model (1991)}

Black and Karasinski (BK) developed a model, within a discrete time framework, where the target rate, mean reversion rate and local volatility are deterministic functions of $t$, see (Svoboda, 2004). The Black-Karasinski model (1991) assumes that $r$ evolves to:

$$
d \ln r_{t}=\left(\theta_{t}-\phi_{t} \ln r_{t}\right) d t+\sigma_{t} d w_{t} .
$$

Black-Karasinski in a similar way to Hull-White introduced the "target interest rate" $\mu(t): d \log (r)=\phi_{t}\left[\left(\log \mu_{t}-\log r\right)\right] d t+\sigma_{t} d w_{t}$, thus the Black-Karasinski mode ${ }^{14}$ in discrete time, where $\phi(t)$ or $\phi_{t}$ is:

$$
\phi_{t}=\frac{1}{\tau_{k}}\left(1-\frac{\sigma_{t} \sqrt{\tau_{\phi}}}{\sigma_{t-1} \sqrt{\tau_{\phi-1}}}\right),
$$

where $\tau_{\phi}=t_{t+1}-t_{t}$. Black, Derman, and Toy (1990) proposed a binomial model with the volatility of a short rate $r_{t}$ proportional to $r_{t}$ This is also a single stochastic model, and the interest rate determines the future evolution of all interest rates. Buetow, Hanke, and Fabozzi (2001) suggested that the BDT model follows the following stochastic differential equation: $d \ln (r)=(\theta(t)+\rho(t)) \ln (r) d t+\sigma t d w$. The mean reversion term $\rho(t)$ depends on the interest rate volatility: $\rho(t)=$

Ito integral. The quadratic variation of $x(t)$ is defined as: $x(t)=\int_{0}^{t} b(u)^{2} d u$ or this can be written in differential form as: $d(x)(t)=b(t)^{2} d t$. Sometimes the previous can be written as: $(d(x) t)^{2}=$ $b(t)^{2} d t$.

${ }^{14}$ How this expression appear? When mean-reversion is combined with the lognorm model, we have three time-dependent factors so now the BK model is: $d(\ln r)=(\theta(t)-k(t) \ln r) d t+\sigma(t) d w_{t}$, dropping $\phi(t)$ to be the function of $\sigma(t)$ and if it is allowed $\mu(t)$ to be the target interest rate, i.e. the reversion rate, then: $d \ln r=\phi(t)(\theta(t)-\phi(t) \ln r) d t+\sigma d w_{t}$ here $\phi(t)$ is a mean-reversion. 
$\frac{d}{d t} \ln (\sigma(t))=\frac{\sigma^{\prime}(t)}{\sigma(t)}$. This translates into: $d \ln (r)=\left(\theta(t)+\frac{\sigma^{\prime}(t)}{\sigma(t)}\right) \ln (r) d t+\sigma t d w$, where $w$ is a standard Brownian motion under a risk-neutral probability measure, $\sigma_{t}$ is an instant short rate volatility. In the specification of the binomial tree BK model, the mean reversion may be equated to the rate of change of local volatility, as the short-term interest rate gets closer to the target rate: $\phi_{t}=\frac{1}{\tau_{t}}-\frac{\sigma_{t}}{\sigma_{t-1} \sqrt{\tau_{t}} \sqrt{\tau_{t-1}}}$. In the previous equation $\tau_{t}=t_{t+1}-t_{t}$, from there: $\frac{1}{\sqrt{\tau_{t}}}=\frac{1 \pm \sqrt{1+4 \phi\left(\frac{\sigma_{t-1}}{\sigma_{t}}\right)^{2} \tau_{t-1}}}{2 \sqrt{\tau_{t-1}}\left(\frac{\sigma_{t-1}}{\sigma_{t}}\right)}$ and now by definition $\frac{1}{\sqrt{\tau_{t}}}>0$ we have cf. (Svoboda, 2004):

$$
\tau_{t}=\tau_{t-1}\left(\frac{4\left(\frac{\sigma_{t-1}}{\sigma_{t}}\right)^{2}}{1+\sqrt{1+4 \phi\left(\frac{\sigma_{t-1}}{\sigma_{t}}\right)^{2} \tau_{t-1}}}\right) .
$$

For $\phi(t)>0$ i.e. positive mean reversion speed, $\tau_{t}-\tau_{t-1} \downarrow$ and $\phi(t) \gg 0 \uparrow$, the more pronounced is $\tau_{t}-\tau_{t-1} \downarrow$.

\section{The Heath-Jarrow-Morton model (HJM) (1992)}

This model ${ }^{15}$ is generated through Heath, Jarrow, and Morton, 1990, 1991, 1992), who formulated the dynamics of the forward rate curve $f(t, T)$ where $T$ is a time of maturity, starting from a given initial curve $f(0, T)$. They showed that the curve's arbitrage free risk-neutral dynamics is determined by the forward-rate volatilities $(t, T)$ :

$$
d f(t . T)=\int_{t}^{T} \sigma(t, s) d s \sigma(t, T) d t+\sigma(t, T) d w_{t} .
$$

This is effectively infinite dimensional SDE (Jamshidian, 2010), driven by the finite dimensional Brownian motion. Regarding the volatility and the Gaussian interest rate (Jamshidian, 1991) showed: $d r t=\left(\frac{d f(0, t)}{d t}+v(t)+\kappa(t)(f(t, 0)-\right.$ $r(t))) d t+\sigma(t) d w_{t}$, where the volatility assignment operator is: $v(t):=$ $\int_{0}^{t} \sigma^{2}(s, t) d s$. The bond and option prices $C$ are functions $C(r, t)$ and satisfy the

15 The HJM methodology encompasses several new concepts: First a stochastic structure is imposed on the forward rate, next the contingent claim prices are not dependent on the market prices of risk, and third, the evolution of term structure is determined by the short-term interest rate. 
PDE: $\frac{\partial C}{\partial t}+\left(\frac{d f(0, t)}{d t}+v(t)+\kappa(t)(f(t, 0)-r(t))\right) \frac{\partial C}{\partial r}+\frac{1}{2} \sigma^{2}(t) \frac{\partial^{2} C}{\partial r^{2}}$, where finite-difference implementation is enabled and so: $f(t, T)=f(t, 0)+e^{-\int_{t}^{T} \kappa_{s} d_{s}}$ $\left(r_{t}-f(0, t)+v(t)+\beta(t, T)\right)$, where: $\beta(t, T):=\int_{t}^{T} e^{\int_{s}^{T} \kappa_{u} d_{u}} d s$. As for zerocoupon bond prices $P(t, T)$, they are by definition related to forward rates: $f(t, T)=$ $-\frac{\partial \log (P(t, T))}{\partial T} \cdot(P(T, T)=1)$, and where:

$$
P(t, T)=\frac{P(0, T)}{P(0, t)} e^{\beta(t, T)(f(t, 0)-r(t))-\frac{1}{2} v(t) \beta^{2}(t, T)} .
$$

This equation makes a valuation of a coupon bond at each exercised date of a Bermudan option ${ }^{16}$. The fundamental solution $C(t, r)$ of PDE for $t \leq T$ satisfies: $C\left(r_{t}, t\right)=\int_{t}^{T} G(t, R, T) C(R, T) d R$ where:

$$
G(t, R, T)=P(t, T)=\frac{e^{-\frac{(R-f(t))^{2}}{2(V(T)-v(t))}}}{\sqrt{2 \pi(v(T)-v(t))}} .
$$

For a fixed maturity, $f(t, T)$ is an Ito process ${ }^{17}$ satisfying: $d f(t, T)=\alpha(t, T) d t+$ $\sigma(t, T) d \mathcal{W}(t)$. Here $\alpha(t, T) ; \sigma(t, T)$ depend upon $\mathcal{F}_{t}=\sigma(\{\mathcal{W}(s): s \leq t\})$. Some peculiar conditions in this model are as follows:

(i) $\forall T, \sigma(t, T) ; \alpha(t, T)$, depend on history $\mathcal{F}_{t}$ of $\mathcal{W}_{s}$ where $t \leq s \leq T$;

(ii) $\int_{0}^{T} \sigma^{2}(t, T) d t ; \int_{0}^{T}|\alpha(t, T)| d t$ are finite $\int_{0}^{T} \int_{0}^{s}|\alpha(t, s)|$ is finite;

(iii) $f(0, T)$ is deterministic and satisfies, $\int_{0}^{T}|f(0, u)| d u<\infty$;

(iv) $E\left[\left|\int_{0}^{u} \sigma(t, u) d \mathcal{W} u\right| d u \mid\right]<\infty$, see (Cairns, 2004).

16 A Bermuda option is a type of exotic options contract that can only be exercised on predetermined dates, often on one day every month. Exotic options are hybrid securities that are often customizable to the needs of the investor.

${ }^{17}$ Probability triple is $(\Omega, \mathcal{F}, \mathcal{P})$, where $\omega \in \Omega$ under $\mathcal{P}$ and $\mathcal{F}_{t}=\sigma(\{\mathcal{W}(u, \omega): 0 \leq u \leq t\})$ is a sigma algebra, $x(t, \omega)$ is a stochastic process adapted to $\mathcal{F}_{t}, L^{2}(0, T)$ is a class of functions $g(t, \omega):[0, \infty) \times \Omega \rightarrow \mathbb{R}$, and $E\left\{\int_{0}^{T} g(t, \omega)^{2} d t\right]<\infty, h(t, \omega)$ is an elementary function, $e_{j}(\omega)$ are a set of function values, $h(t, \omega)=\sum_{j=0}^{N} e_{j}(\omega) I_{\left[t_{j}, t_{j+1}\right]}(t) . \exists h(t, \omega) \subset L^{2}(0, t) ; E\left[\int_{0}^{T}(g(t, \omega)-\right.$ $\left.\left.h_{\tau}(t, \omega)\right)^{2} d t\right]$. Ito integral of $g(t, \omega)$ then is defined as: $\int_{0}^{T} g(t, \omega) d \mathcal{W}(t, \omega)=$ $\lim _{\tau \rightarrow \infty} \int_{0}^{T} h_{\tau}(t, \omega) d \mathcal{W}(t, \omega)$, where $\tau=T-t$, while in the SDE case, suppose that $d x(t)=\alpha(t) d t+$ $b(t) d \mathcal{W}(t)$, let $f(t, x):[0, \infty) \times \mathbb{R} \rightarrow \mathbb{R}$ be a $\mathcal{C}^{2}$ function and let $\mathcal{Y}(t)=f(t, x(t))$ be a diffusion process, then Ito's formula for one dimensional diffusion processes is given as: $d \mathcal{Y}(t)=\frac{\partial f}{\partial t}(t, x(t))+$ $\left.\frac{\partial f}{\partial x}(t, x(t)) \alpha(t)+\frac{1}{2} \frac{\partial^{2} f}{\partial t^{2}}(t, x(t)) b(t)^{2}\right] d t+\frac{\partial f}{\partial x}(t, x(t)) b(t) d \mathcal{W}(t)$. 
Lemma 2. $\forall T$; zero coupon bond price in the HJM model follows the Ito process of the form, see also (Filipovic, 2009):

$$
\begin{aligned}
\mathcal{P}(t, T)=\mathcal{P}(0) & +\int_{0}^{T} \mathcal{P}(s, T)(r(s)+b(s, T)) d s \\
& +\int_{0}^{t} \mathcal{P}(s, T) \mathcal{v}(s, T) d \mathcal{W}(s) ; t \leq T .
\end{aligned}
$$

In the previous expression: $v(s, T)=-\int_{s}^{T} \sigma(s, u) d u$; is the Treasury bond volatility and $b(s, t)=-\int_{s}^{T} \alpha(s, u) d u+\frac{1}{2}\|v(s, T)\|^{2}$.

Proof: By the Fubini theorem ${ }^{18}$ for stochastic integrals one obtains here:

$$
\begin{aligned}
& \log \mathcal{P}(t, T)=-\int_{0}^{T} f(0, u) d u \\
& -\int_{0}^{T} \int_{0}^{t} \alpha(s, u) d u-\int_{0}^{T} \int_{0}^{t} \sigma(s, u) d \mathcal{W}(s) d u=-\int_{0}^{T} f(0, u) d u \\
& +\int_{0}^{t}\left(b(s, T)-\frac{1}{2}\|v(s, T)\|^{2}\right) d s \\
& +\int_{0}^{t} v(s, T) d \mathcal{W}(s) \\
& +\int_{0}^{t}\left(f(0, u)+\int_{0}^{u} \alpha(s, u) d s+\int_{0}^{u} \sigma(s, u) d \mathcal{W}(s)\right) d u \\
& =\log \mathcal{P}(0, T) \\
& +\int_{0}^{t}\left(r(s)+b(s, T)-\frac{1}{2}\|v(s, T)\|^{2}\right) d s+\int_{0}^{t} v(s, T) d \mathcal{W}(s) \square
\end{aligned}
$$

Previously $r(u)=\left(f(0, u)+\int_{0}^{u} \alpha(s, u) d s+\int_{0}^{u} \sigma(s, u) d \mathcal{W}(s)\right)$.

\section{Simulate the price of a bond using a Hull-White one-factor model until the bond's maturity}

Here the authors used MATLAB to simulate the price of a bond using the Hull-White one-factor model ${ }^{19}$ until the bond's maturity. First, they defined the zero-curve data, then the CouponRate $=0$, followed by the Hull-White parameters: $\alpha=0.1$; and $\sigma=0.01$.

18 Consider $\mathbb{R}^{D}$ valued stochastic process $\phi=\phi(\omega, t, s)$, with two indices $0 \leq t \leq s$, satisfying the following properties: $\phi$ is $\operatorname{prog}_{T} \otimes \mathcal{B}[0, T]$-measurable sup $\|\phi(t, s)\|<\infty$. Moreover, $\int_{0}^{T}\left(\int_{0}^{T} \phi(t, s) d \mathcal{W}(t)\right) d s=\int_{0}^{T}\left(\int_{0}^{T} \phi(t, s)\right) d \mathcal{W}(t)$.

${ }^{19}$ The Hull-White one-factor model is specified using the zero curve, alpha, and sigma parameters. Zero curve is used to evolve the path of the future interest rates. 
HW1F = HullWhite1F (RateSpec, alpha, sigma). Then the simulation parameters are defined:

nTrials $=100 ;$ nPeriods $=12 * 5 ; \Delta$ Time $=1 / 12$. The simulation gives the following result:

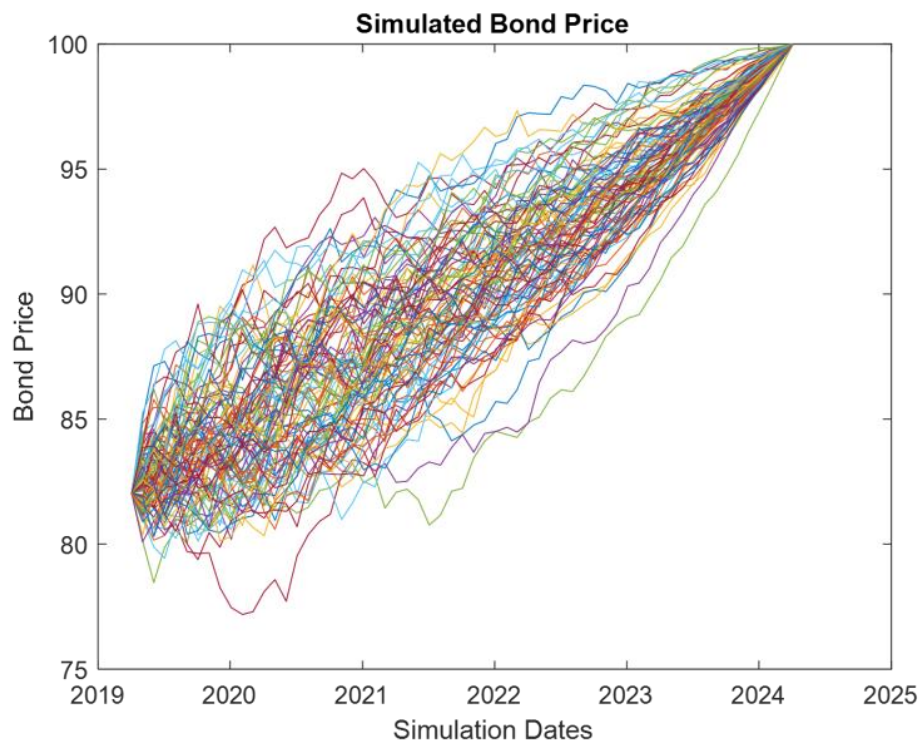

Fig. 1. Simulation of the price of a bond using the Hull-White one-factor model until the bond's maturity $\alpha=\mathbf{0} .1$; and $\boldsymbol{\sigma}=\mathbf{0 . 0 1}$

Source: authors' own calculation.

Simulated prices of the bond are converging in approximately five years, since the start of the simulation.

\subsection{Simulate the total return of a bond portfolio until maturity using the Hull-White one-factor model}

Now there is a simulation of total return of a bond portfolio until maturity by using the Hull-White one-factor model, the authors define zero rates: Zero Rates $=[-0.01-0.009$ $-0.0075-0.003-0.002-0.0010 .0020 .0075]$, and zero dates from which there are settle date, zero times 12, where zero times are ZeroTimes $=[3 / 12$ 6/12 157102030$]$, coupon rates are CouponRate $=[0.035 ; 0.04 ; 0.02 ; 0.015 ; 0.042]$. The defined Hull-White parameters are $\alpha=0.1$; and $\sigma=0.01$. As can be seen in the following graph, the simulated portfolio bond returns first are converging around zero returns but not zero, and afterwards they are diverging. References to these models in the Matlab financial toolbox are in (Brigo and Mercurio, 2006) and (Hull, 2011). 


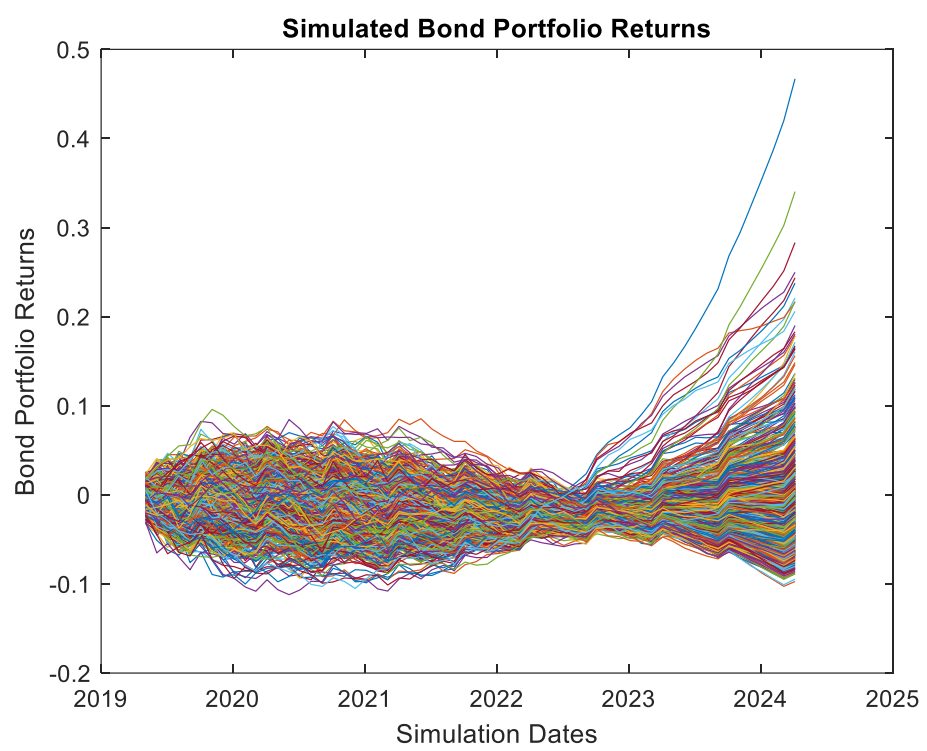

Fig. 2. Simulation of the total return of a bond portfolio until maturity using the Hull-White one-factor model maturity $\boldsymbol{\alpha}=\mathbf{0 . 1}$; and $\boldsymbol{\sigma}=\mathbf{0 . 0 1}$

Source: authors' own calculation.

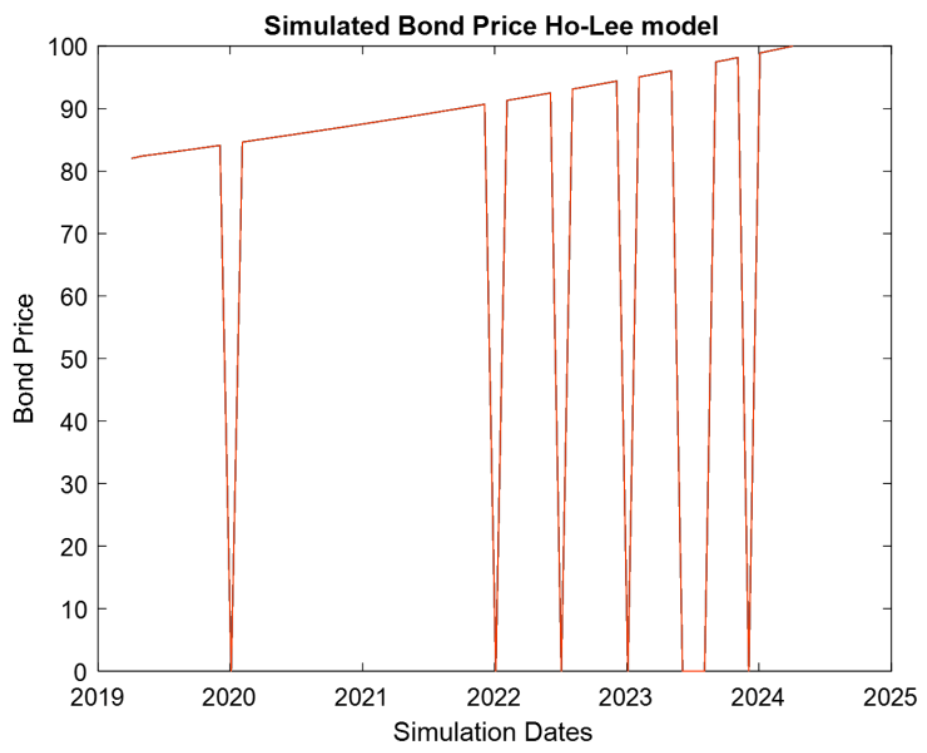

Fig. 3. The Ho-Lee model $\boldsymbol{\alpha}=\mathbf{0}$; and $\boldsymbol{\sigma}=\mathbf{0 . 0 1}$

Source: authors' own calculation. 
When $\alpha=0$ the Hull-White model becomes the Ho-Lee model and the simulated bond price is depicted in the following graph ${ }^{20}$.

\section{The Cox-Ingersoll-Ross process}

The Cox-Ingersoll-Ross model ${ }^{21}$ is a continuation in the equilibrium short-rate models. This exercise of the CIR model uses the following parameters: $t=\left[\begin{array}{ll}0 & 0.25\end{array}\right]$; observation times, $a=0.2$; mean-reversion parameter, $b=0.05$; long-term mean, $s=0.1$; volatility $r_{0}=0.04$; starting value. The resulting empirical distribution is similar to normal:

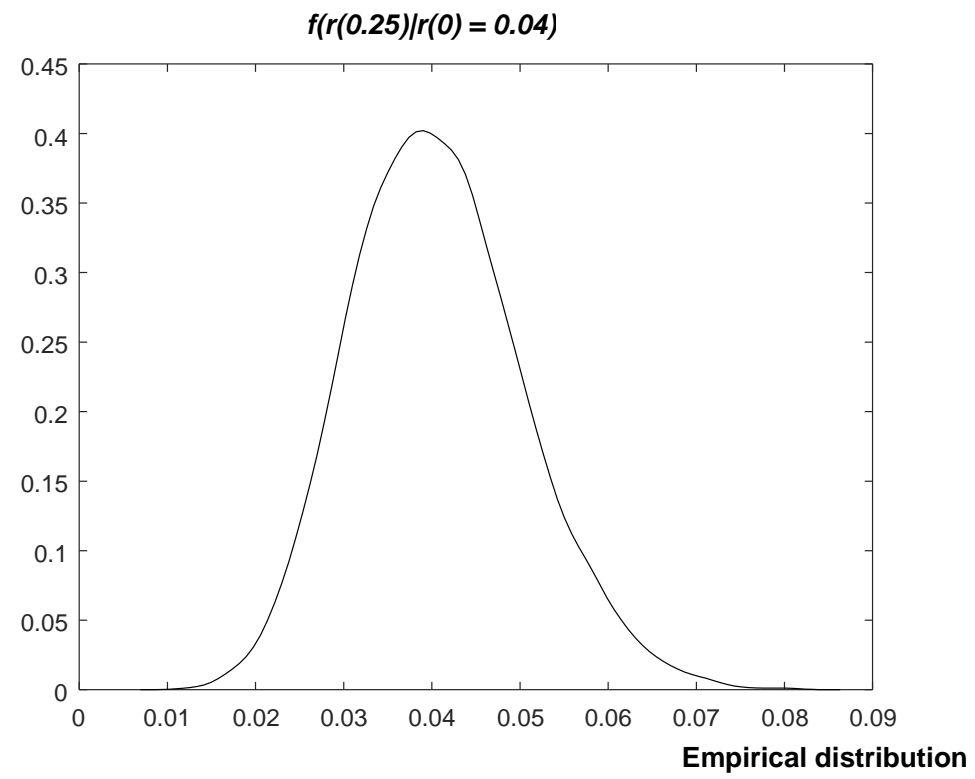

Fig. 4. The Cox-Ingersoll-Ross process empirical distribution of the interest rates

Source: authors' own calculation.

${ }^{20}$ In their basic forms these models are presented as follows: the Hull-White model $d r=$ $[\theta(t)-\alpha(t) r(t)] d t+\sigma(t) d \mathcal{W}(t)$. The Ho-Lee model is given as: $d r(t)=\theta(t) d t+\sigma(t) d \mathcal{W}(t)$. Where $d r$ is the change in the short-term interest rate over a small interval, $\theta(t)$ is a function of time determining the average direction in which $r$ moves, chosen such that movements in $r$ are consistent with today's zero coupon yield curve, $\alpha$ is the mean reversion rate, $d t$ is a small change in time, $\sigma$ is the annual standard deviation of the short rate, $\mathcal{W}$ is the Brownian motion.

${ }^{21}$ The CIR process satisfied the following equation: $d r(t)=k(\theta-r(t)) d t+\sigma \sqrt{r t} d w(t)$. 
In the second CIR, example parameters are: $t=0: 0.05 ; a=0.2 ; b=0.05$; $s=[0.01 .1 .5] ; r_{0}=0.04$.

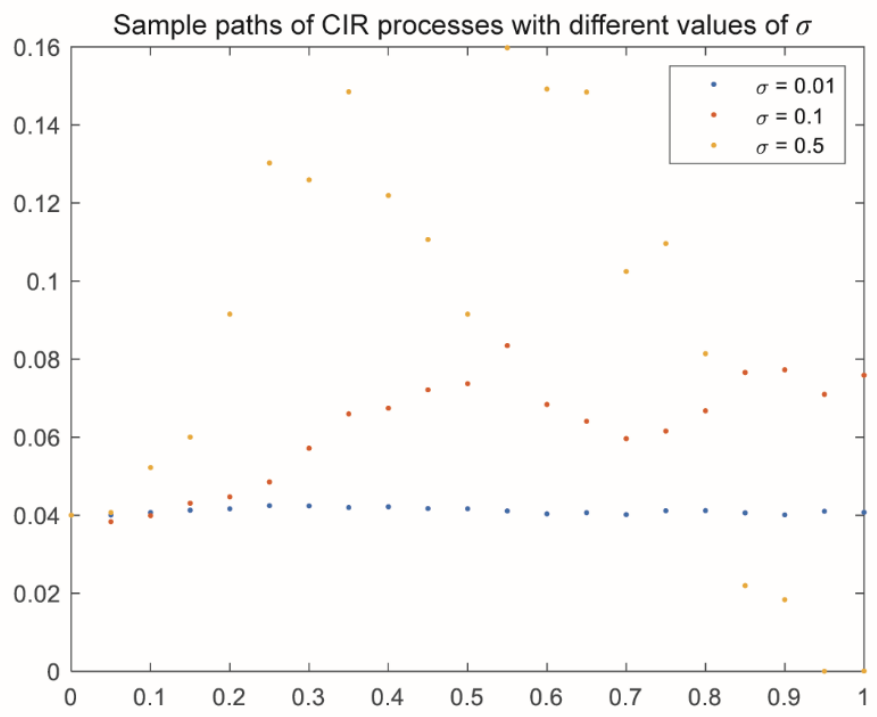

Fig. 5. Sample paths of CIR processes with different values of $\boldsymbol{\sigma}=\mathbf{0 . 0 1}, \mathbf{0 . 0 2}, \mathbf{0 . 5}$

Source: authors' own calculation.

From the previous graph one concludes that for higher volatility, the parameter sample path of the CIR processes has a higher drift.

\section{The Vasicek model}

The Vasicek function is given as: $V=f(\alpha, \mu, \sigma, r)^{22}$ and the model is:

$$
d r(t)=\alpha(\mu-r(t)) d t+\sigma d \mathcal{W} .
$$

From the previous graph it can be seen that on the first graph, the left amplitude is positive when calculating from trough ${ }^{23}$ to peak or a bullish retracement, which is a term to describe a minor pullback (a moderate drop in a stock or commodities pricing chart in an otherwise trend of recent peaks, this can be also called a consolidation, or an asset oscillating between well-defined patterns of trade; i.e. market indecisiveness).

${ }^{22}$ Here $\alpha$ is the speed of the mean reversion, $\mu$ is the risk-neutral long-term mean of the short rate, $\sigma$ is the volatility or std. of the short rate, $r$ is the current short rate at time $t$.

${ }^{23}$ A trough is the stage of the economy's business cycle that marks the end of a period of declining business activity and the transition to expansion - or as in this example - a trough is the low end of price decline and at the same time a point of transition to a high peak. 

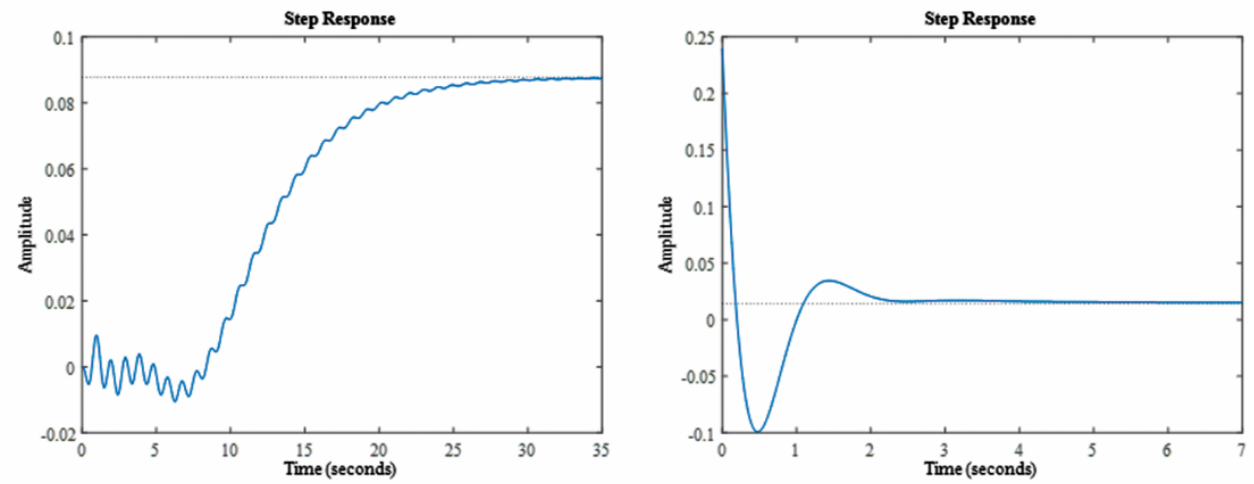

Fig. 6. The Vasicek model Step response and the price amplitude ${ }^{24}$

Source: authors' own calculation.

From the above graphs it can be seen that a convergence takes more steps when the security's price is going through a positive shift, which is not the case in a minor negative pullback. Pricing drops are relatively short in duration. The amplitude also allowed to estimate the volatility (level) or the amount of risk present in a particular investment. In the previous example the arguments in the function were: $r=0.07$; $\alpha=0.3 ; \mu=0.08 ; \sigma=0.01$, and the maturity matrix is given as mat $=$ [0: step: 10].

\section{The Vasicek and CIR simulation of the daily short rates}

An analytical solution in the Vasicek (1977) model is given as:

$$
\begin{gathered}
\mathcal{B}=\frac{1-\exp (-\alpha \cdot m a t)}{\alpha} ; \mathcal{A}=\left(\bar{r}-\frac{\sigma^{2}}{2 * \alpha^{2}}\right) \cdot(B-m a t)-\frac{\sigma^{2} \cdot B^{2}}{4 \cdot \alpha} ; \\
\mathcal{P}=\exp (\mathcal{A}-\mathcal{B} \cdot r) ;
\end{gathered}
$$

while an ODE solution in Matlab toolbox for the Vasicek (1977) function $d y=$ vasice $_{\text {ode }}(t, y)$ is given as:

$$
\begin{gathered}
d y(1,1)=\left(\frac{1}{2}\right) \cdot \sigma^{2} \cdot y(2)^{2}-\bar{r} \cdot \alpha \cdot y(2) ; d y(2,1)=1-\alpha \cdot y(2) ; \\
A_{\text {ode }}=y(:, 1) ; B_{\text {ode }}=y(:, 2) ; \\
P_{\text {ode }}=\exp \left(A_{\text {ode }}-B_{\text {ode }} \cdot r\right)
\end{gathered}
$$

${ }^{24}$ Amplitude is the difference in a security's price from its wave cycle through (bottom) to the peak of its price movement over a period of time. 
The Vasicek model ${ }^{25}$ is depicted in the following graph that presents the convergence in the Euribor yields.

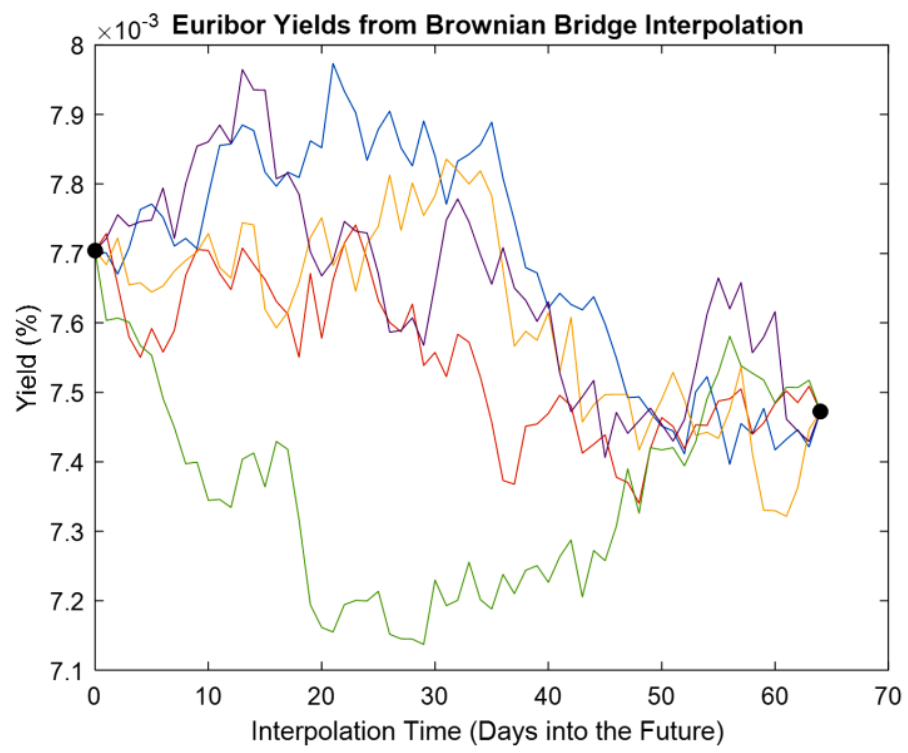

Fig. 7. The univariate Vasicek interest rate model

Source: authors' own calculation.

From the previous graph one can see that convergence in Euribor yields is achieved in 60-70 days. Interpolations show the achievement of equilibrium yield of approximately $7.4 \%$. Once again, the CIR model was assumed to follow this differential equation:

$$
d r(t)=k(\theta-r(t)) d t+\sigma \sqrt{r t} d w(t) .
$$

In the previous equation ${ }^{26}: k, \sigma, \theta>0$ with $2 k \theta>\sigma^{2} w$ is a Brownian motion under risk-free measure (for a reference see (Aït-Sahalia, 1996; Glasserman, 2004).

25 Here also the Vasicek functions contain following arguments $r=0.07 ; \alpha=0.3 ; \mu=0.08$; $\sigma=0.01$.

26 Forward interest rate stochastic integral will be: $f(t, T)=\int_{0}^{t} \sigma_{0} r^{\gamma} e^{-\lambda(s-u)} d s d u+$ $\int_{0}^{t} \sigma_{0} r^{\gamma} e^{-\lambda(T-u)} d \widetilde{\mathcal{W}}(u)$. Thus, from here: $\quad d f(t, T)=\left[\sigma_{0} r^{2 \gamma}(t) \mathcal{B}(t, T) e^{-\lambda(T-t)}\right] d t+$ $\sigma_{0} r^{\gamma} e^{-\lambda(T-t)} d \widetilde{\mathcal{W}}(u)$, where in previous: $\mathcal{B}(t, T)=\int_{t}^{T} \sigma_{0} e^{-\lambda(s-t)} d s=\frac{1}{\lambda} \sigma_{0}\left[1-e^{-\lambda(T-t)}\right]$. Price at the maturity will be: $P(t, T)=\exp -\left[\pi^{\prime}(t, T)[r(t)-f(0, t)]+\frac{1}{2} \pi^{\prime 2}(t, T) \psi(t)\right]$, where: $\psi(t)=$ $\int_{0}^{t} \sigma^{2}(s, t) d s$. 


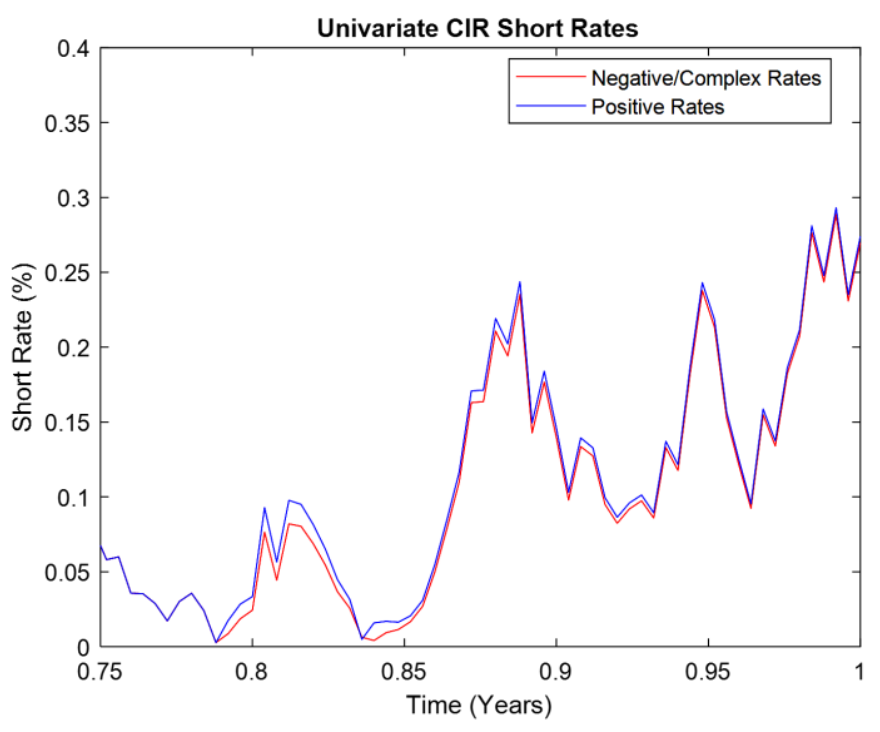

Fig. 8. Univariate CIR short rates

Source: authors' own calculation.

From the previous graph one can see the evolution of the short rate in one years' time by using the CIR (1985) model.

\section{The Binomial lattice model for bond price and interest rate modelling}

These models can be viewed as approximations to the more sophisticated models. The study used martingale ${ }^{27}$, see (Feller, 1971) pricing on this lattice to compute the bond prices, which means using no-arbitrage models. The value process associated with the trading strategy is defined as: $V_{t}=\left\{\begin{array}{l}\sum_{i=0}^{N} \theta_{i} \mathcal{B}_{0}, t=0 \\ \sum_{i=0}^{N} \theta_{i} \mathcal{B}_{t}, t \geq 1\end{array}\right.$, where $\theta$ are trading strategies (traders profiles), $V_{t}=f(\theta)$ is the value process, $N$ is time or number of available securities or bonds, in this case $\mathcal{B}$ bonds.A self-finance strategy is: $V_{t}=\sum_{i=0}^{N} \theta_{t+1} \mathcal{B}_{t}$, the value of portfolio just before trade is equal to the value of the portfolio just after trading: $V_{t+1}-V_{t}=\sum_{i=0}^{N} \theta_{t+1}\left(\mathcal{B}_{t+1}-\mathcal{B}_{t}\right)$, with a coupon bond payment $C_{t+1}$, then $\theta_{t}$ is a self-financing strategy if: $V_{t+1}-V_{t}=\sum_{i=0}^{N} \theta_{t+1}\left(\mathcal{B}_{t+1}+C_{t+1}-\mathcal{B}_{t}\right)$.

${ }^{27}$ Equivalent martingale measure $Q \Rightarrow P(A)=Q(A)$ where $A$ is a type of bond is given as: $\frac{\mathcal{B}_{t}}{N_{t}}=$ $E_{t}^{Q}\left[\sum_{i=t+1}^{t+s} \frac{C_{i}}{N_{i}}+\frac{\mathcal{B}_{t+s}}{N_{t+s}}\right]$, the deflated price of a bond $\frac{\mathcal{B}_{t+s}}{N_{t+s}}$ is a $Q$-expectation of the terminal deflated value of any bond, so that there is no arbitrage. 
By definition, the price of a discount bond ${ }^{28}$ with maturity date $T$ is given as, see ( $\mathrm{Li}$, Ritchken, and Sankarasubramanian, 1995): $P(t, T)=e^{-\int_{t}^{T} f(t, s) d s}$. Ritchken and Sankarasubramanian (1995) identify the class of volatility structures that permit the terms structure to be presented by a two-state Markovian model ${ }^{29}$. To provide an illustration of the binomial lattice no-arbitrage models, the study used the Matlab code by Krishna (2021). Hence now the price of a bond is given as: $P(t, T)=$ $\left(\frac{P(0, T)}{P(0, t)}\right) e^{\beta(t, T)\left(r(T)-f(0, t)-\frac{1}{2} \beta^{2}(t, T) \phi(t)\right.}$, where $\beta(t, T)=\int_{t}^{T} k(t, u) d u$, and $\phi(t)=$ $\int_{0}^{t} \sigma_{f}^{2}(u, u) k^{2}(u, t) d u$. In this example $r_{0}=0.07 ; u=1.3 ; d=0.9 ; T=5$; $k=90$. The results are presented in the following tables. From the short-rate dynamics of interest rate and accordingly the bond price, one can find the put/call option price.

Table 1. Short-rate dynamics of the interest rate model

\begin{tabular}{|l|l|l|l|l|}
\hline 0.07 & 0.0630 & 0.0567 & 0.51 & 0.0459 \\
\hline 0 & 0.0910 & 0.0819 & 0.0737 & 0.0663 \\
\hline 0 & 0 & 0.1183 & 0.1065 & 0.0958 \\
\hline 0 & 0 & 0 & 0.1538 & 0.1384 \\
\hline 0 & 0 & 0 & 0 & 0.1999 \\
\hline
\end{tabular}

Source: authors own calculation.

Table 2. Underlying assets bound price

\begin{tabular}{|l|l|l|l|l|l|}
\hline 0.667 & 0.7555 & 0.834 & 0.901 & 0.9561 & 1.0000 \\
\hline 0 & 0.6718 & 0.7722 & 0.8617 & 0.9378 & 1.0000 \\
\hline 0 & 0 & 0.6935 & 0.8093 & 0.9126 & 1.0000 \\
\hline 0 & 0 & 0 & 0.7418 & 0.8784 & 1.0000 \\
\hline 0 & 0 & 0 & 0 & 0.8334 & 1.0000 \\
\hline 0 & 0 & 0 & 0 & 0 & 1.0000 \\
\hline
\end{tabular}

Source: authors own calculation.

Table 3. Binomial latice for call price

\begin{tabular}{|l|l|l|l|l|}
\hline 1.3466 & 2.1487 & 3.2225 & 4.4660 & 5.6090 \\
\hline 0 & 0.733 & 1.3457 & 2.3444 & 3.7788 \\
\hline 0 & 0 & 0.2537 & 0.5674 & 1.2556 \\
\hline 0 & 0 & 0 & 0 & 0 \\
\hline 0 & 0 & 0 & 0 & 0 \\
\hline
\end{tabular}

Source: authors own calculation.

28 The forward rate diffusion process is given as: $d f(t, T)=\mu_{f}(t, T)+\sigma_{f}(t, T) d \mathcal{W}_{t}, f(0, T)$, $T>t$, where $\mu_{t}(t, T)=\sigma_{f}(t, T) \int_{t}^{T} \sigma_{f}(t, s) d s$.

${ }^{29} \sigma_{f}(t, T)=\sigma_{f}(t, t) k(t, T)$ and $(t, T)=e^{-\int_{t}^{T} \kappa(x) d x} ; \sigma_{f}(t, t)$ is the volatility of the spot rate, $\kappa(x)$ is an exogenously provided deterministic function. 
Table 4. Binomial lattice for put option

\begin{tabular}{|l|l|l|l|l|}
\hline 0.655 & 0.212 & 0 & 0 & 0 \\
\hline 0 & 1.1896 & 0.4507 & 0 & 0 \\
\hline 0 & 0 & 2.1450 & 0.9753 & 0 \\
\hline 0 & 0 & 0 & 3.8221 & 2.1583 \\
\hline 0 & 0 & 0 & 0 & 6.6616 \\
\hline
\end{tabular}

Source: authors own calculation.

\section{The Black-Karasinski tree model}

In this model ${ }^{30}$, compounding $=-1$ and rates $=[0.0275 ; 0.0312 ; 0.0363 ; 0.0415]$. The resulting tree models are as follows:
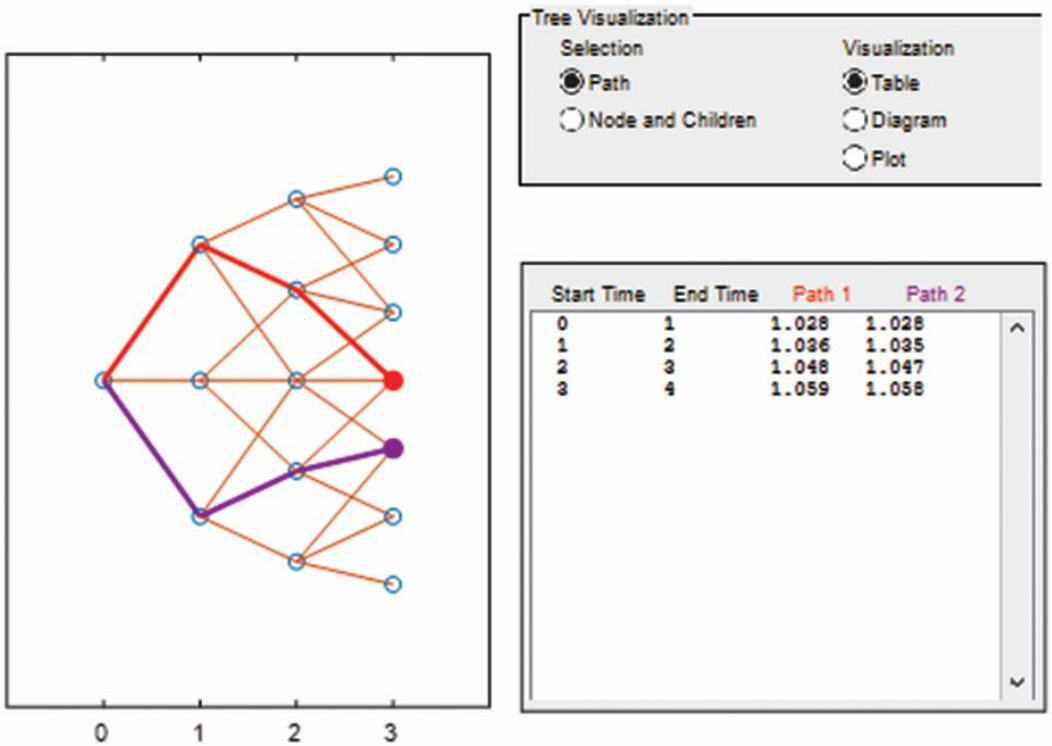

Fig. 9. The Black-Karasinski model table presentation

Source: authors' own calculation.

${ }^{30}$ In this extended exponential Vasicek model $r_{t}=\exp \left(z_{t}\right) ; d z_{t}=k\left[\theta_{t}-z_{t}\right] d t+\sigma d \mathcal{W}_{t}$, and the BK model is presented as: $d \ln r_{t}=\left(\theta_{t}-\phi_{t} \ln r_{t}\right) d t+\sigma_{t} d w_{t}$ where $\phi_{t}=\frac{1}{\tau_{k}}\left(1-\frac{\sigma_{t} \sqrt{\tau_{\phi}}}{\sigma_{t-1} \sqrt{\tau_{\phi-1}}}\right)$ and $\tau_{\phi}=t_{t+1}-t_{t}$ 

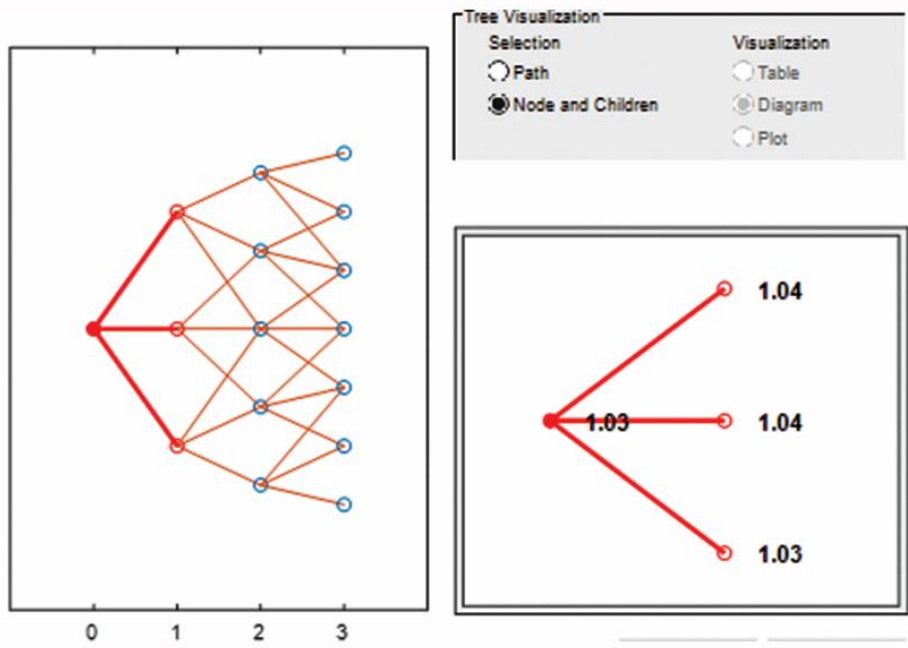

Fig. 10. The Black-Karasinski model node presentation

Source: authors' own calculation.

In the next two figures the Black-Karasinski model is presented as a plot and path diagram presentation.

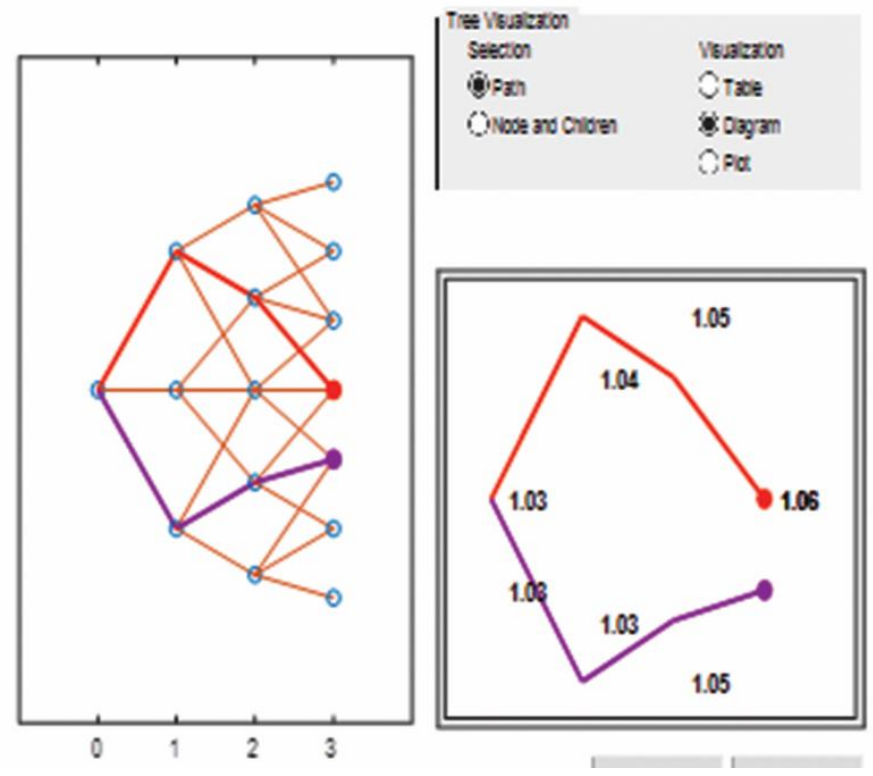

Fig. 11. The Black-Karasinski model path diagram presentation

Source: authors' own calculation. 


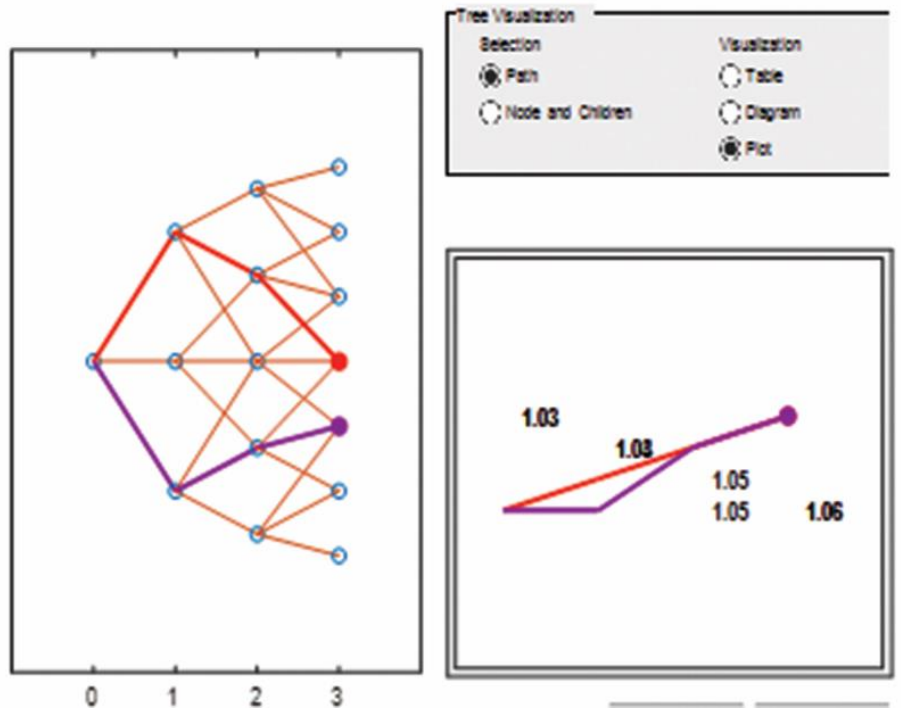

Fig. 12. The Black-Karasinski model plot presentation Source: authors' own calculation.

The conclusion in this 'no-arbitrage' model is that the starting price does not differ much from the closing price, and the ratio between the two is close to 1 , i.e. $\frac{1.03}{1.06}=$ 0.9717 .

\section{The Heath-Jarrow-Morton interest-rate tree}

In this model ${ }^{31}$ the following parameters are given in order to estimate the path of bond prices:

Rates $=[0.1 ; 0.11 ; 0.12 ; 0.125 ; 0.13] ;$ Volatility $=[0.2 ; 0.19 ; 0.18 ; 0.17 ; 0.16] ;$ and the CurveTerm $=[1 ; 2 ; 3 ; 4 ; 5]$;

31 The fundamental result due to the HJM model regarding the diffusion forward rates is: $d f(t, T)=\sigma(t, T)\left(\int_{t}^{T} \sigma(t, s) d s\right) d t+\sigma(t, T) d \mathcal{W}_{t}$.or $\quad d r_{t}=b\left(t, r_{t}\right) d t+\sigma\left(t, r_{t}\right) d \mathcal{W}_{t}, \quad b \quad$ is not correlated to $\sigma$ due to no-arbitrage. 


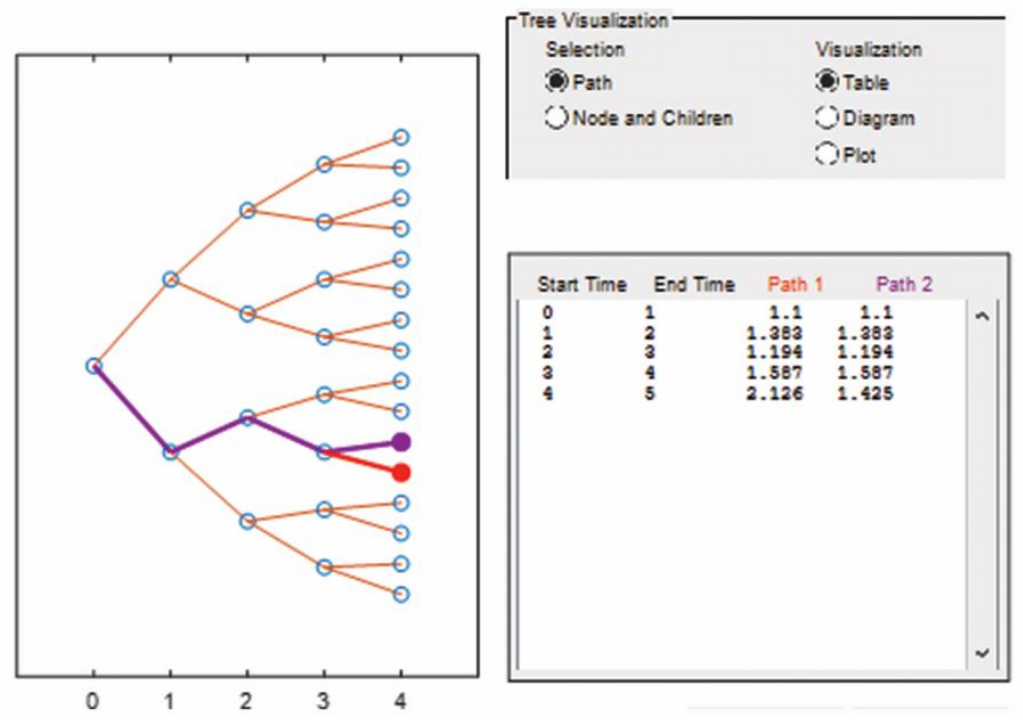

Fig. 13. The Heath-Jarrow-Morton interest rate tree table presentation

Source: authors' own calculation.
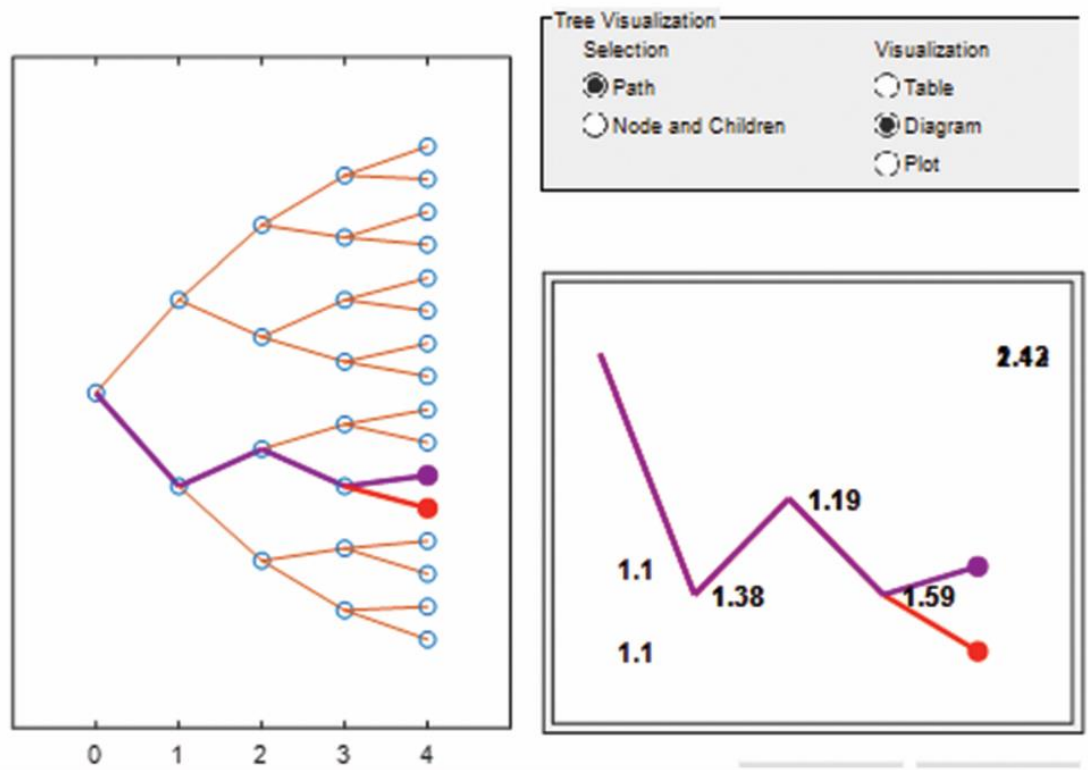

Fig. 14. The Heath-Jarrow-Morton interest rate tree diagram presentation

Source: authors' own calculation. 

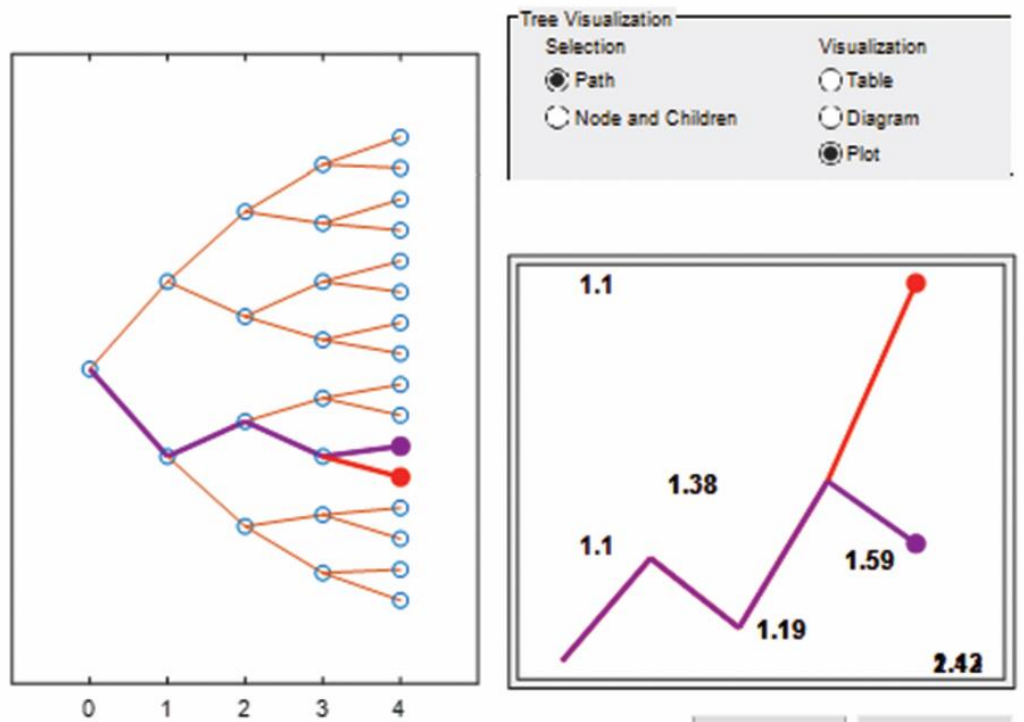

Fig. 15. The Heath-Jarrow-Morton interest rate plot presentation

Source: authors' own calculation.

This model gives the solution for the closing prices of $[1.425 ; 2.126]$ while the first price is 1.1 .

\section{Conclusion}

The Cox et al. (1985) model, and the Vasicek (1977) model are similar, they assume that all interest rate contingent claims are based on short-term interest rates. The mean-reversion term in this model assumes that the yield curve on a bond or security cannot follow random walk as in a stock movement. The mean reversion term meant that short-term rate $r$ is higher than the long-term $\theta$, so that the short-term rate would fall adjusting gradually to the long-term interest rate. Long-term interest rates will follow random walk and a martingale sequence with finite means such that the conditional expectation of $x_{n+1}$ is given as: $\left(x_{n+1} \mid x_{0}, \ldots, x_{n}\right)=x_{n}$, see (Mishkin, 1978; Pesando, 1979). Conversely the short-term rate is lower than the long-term interest rate, and it will rise to long-term rate, see (Ho and Lee $(2004)^{32}$. Now the arbitrage-free condition $\frac{\mu-r}{\sigma}=\lambda(r, t)$, where $\lambda$ is the market price of risk. No-arbitrage models are making a departure from economic theory and they assume that the yield curve follows a random movement, just like the model used to describe a stock price movement. One

${ }^{32}$ Dybvig (1989) shows that the one-factor model offers an appropriate first-order approximation for modelling the yield curve movement, i.e. that the yield curve can be confined to exhibit one-factor movement where that factor is only movement in $r$. 
shortcoming of the no-arbitrage models such as the Ho-Lee (1986) and Hull and White (1990) model, the Black-Karasinski model (1991), the Heath, Jarrow and Morton (1992) model and binomial tree models is that interest rate movement does not exhibit mean reversion process, and the volatility of the one-period rate is constant at each node point.The assumption in the no-arbitrage models seems to be more unrealistic, namely: first assuming a perfect capital market ${ }^{33}$, the yield curve can move only up and down, one period interest rate volatility is the same in all of the states of the model, there exists no-arbitrage opportunity in any node point on the binomial lattice. The distribution used in the models is normal or log-normal namely: Vasicek (1977), Hull and White (1990) used normal distribution, while Cox, et al. (1985), Black-Karasinski model (1991) used log-normal distributions. The Heath, Jarrow, and Morton (1992) model has become a popular term structure model in the interest rate derivatives pricing theory. In the HJM (1992) model, the only inputs needed to construct the term structure are the initial yield curve and the volatility structure for all forward rates. No-arbitrage models such as the HJM (1992) model are in general non-Markovian, and contingent models are considered difficult to price with the lattice method. To solve this problem the HJM (1992) model version used in this paper is a single-factor model with a forward volatility structure that depends on the time and the time to maturity, the instantaneous spot rate and forward rate to a fixed maturity. The results showed that convergence in the Hull and White (1990) model was achieved in five periods (years) since the start. Regarding the simulation of the total return on bond portfolio until maturity using the Hull-White one-factor model, the results are that the bond returns first converged around zero returns and afterwards diverged, and negative returns are allowed - meaning that the premium exceeds the income the investor will receive during their holding period. In this model, returns converged in four periods (years) of time. In the simulated CIR model, the conclusion was that volatility was not constant as in the no-arbitrage models, and that the higher volatility parameter sample path of CIR processes has a higher drift. The simulation of the Vasicek model proved that convergence takes more steps when the interest rate is going through a positive shift.When a positive shift of price occurs in the Vasicek model, convergence is achieved in five steps, In the case of a negative pullback of interest rate, convergence is achieved in one step. Binomial lattice models were the first of the no-arbitrage models simulated in this paper. From the example it can be seen that they are more useful since they provide information about short-rate dynamics, underlying asset price and the call price and put option, for binomial lattice models see (Benninga and Wiener, 1999). In the Black-Karasinski model with constant volatility, the conclusion was that when the starting price does not differ much from the closing price, the ratio between the two is close to 1.The HJM model simulated in this paper gives the solution of the closing price with a lower and upper bound. In conclusion it can be confirmed

${ }^{33}$ The capital market is perfect when all of the investors have enough power to change the price of an asset and all of them have access to the same information. On that market, the stock values adjust rapidly to the new information, and stock values should, or reveal, all existing information. 
that there is no single interest rate model that can be used for all the purposes. The authors concluded that since interest rate volatility is fundamental to the valuing of the contingent claims and hedging interest risk, the models based on the rate structure should focus on the dependence on the volatility of the level of the rate. This notion was also put forward in the empirical literature, see: (Chan, Karolyi, Longstaff, and Sanders, 1992).

\section{References}

Ahn, D.-H., and Gao, B. (1999). A parametric nonlinear model of term structure dynamics. Review of Financial Studies, 12, 721-762.

Aït-Sahalia, Y. (1996). Testing continuous-time models of the spot interest rate. Review of Financial Studies, 9(2), 385-426.

Aït-Sahalia, Y. (1999). Transition densities for interest rate and other nonlinear diffusions. Journal of Finance, 54, 1361-1395.

Andersen, T. G., and Lund, J. (1997). Estimating continuous-time stochastic volatility models of the short-term interest rate. Journal of Econometrics, 77(2), 343-377.

Bali, T. G. (1999). An empirical comparison of continuous time models of the short term interest rate. Journal of Futures Markets, 19(7), 777-797.

Benninga, S., and Wiener, Z. (1998). Binomial term structure models. Mathematica in Education and Research, 7(3), 1-10. Retrieved from https://pluto.mscc.huji.ac.il/ mswiener/research/ Benninga73.pdf

Birge, J. R. (2013). Financial engineering. In Gass, S.I., Fu, M.C. (Eds.) Encyclopedia of Operations Research and Management Science. Boston, MA: Springer. https://doi.org/10.1007/978-1-44191153-71144

Björk, T. (2009). Arbitrage theory in continuous time (3rd ed.). Oxford: Oxford University Press.

Björk, T., and Slinko, I. (2006). Towards a general theory of good-deal bounds. Review of Finance, 10, 221-260.

Black, F., and Scholes, M. (1973). The pricing of options and corporate liabilities. Journal of Political Economy, 3, 637-654.

Black, F., Derman, E., and Toy, W. (1990). A one-factor model of interest rates and its application to treasury bond options (PDF). Financial Analysts Journal, 24-32.

Black, F., and Karasinski, P. (1991). Bond and option pricing when short rates are lognormal. Financial Analysts Journal, 47(4), 52-59.

Brennan, M., and Schwartz, E. (1979). A continuous time approach to the pricing of bonds. Journal of Banking \& Finance, 3(2), 133-155.

Brennan, M., and Schwartz, E. (1982). An equilibrium model of bond pricing and a test of market efficiency. Journal of Financial and Quantitative Analysis, 17, 301-329.

Brigo, D., and Mercurio, F. (2006). Interest rate models - Theory and practice. Springer Finance.

Buetow, G. W., Fabozzi, F. J., and Sochacki, J. (2012). A review of no arbitrage interest rate models. Encyclopedia of Financial Models, $I$.

Buetow, G. W. Jr., Hanke, B., and Fabozzi, F. J. (2001). Impact of different interest rate models on bond value measures. The Journal of Fixed Income.

Cairns, A. (2004). Interest rate models: An introduction. Princeton, Oxford: Princeton University Press.

Chan, K. C., Karolyi, G. A., Longstaff, F. A., and Sanders, A. B. (1992). An empirical comparison of alternative models of the short-term interest rate. Journal of Finance, 47, 1209-1227. 
Chen, L. (1996). Stochastic mean and stochastic volatility - A three-factor model of the term structure of interest rates and its application to the pricing of interest rate derivatives. Financial Markets, Institutions \& Instruments, 5, 1-88.

Cox, J. C., Ingersoll, J., and Ross, S. (1980). An analysis of variable rate loan contracts. Journal of Finance, 35, 389-403.

Cox, J. C., Ingersoll J. E., and Ross, S. A. (1985). A theory of the term structure of interest rates. Econometrica, 53, 385-407. doi:10.2307/1911242

Doob, J. L. (1953). Stochastic processes. New York: Wiley.

Dothan, U. L. (1978). On the term structure of interest rates. Journal of Financial Economics, 7, 59-69.

Dybvig, P. H. (1989). Bond and option pricing based on current term structure (Working paper). St. Louis, Missouri: Washington University.

Ewald, Ch.-O. (2007). Introduction to continuous time financial market models. School of Economics and Finance University of St. Andrews.

Fama, E. F. (1984). Term premiums in bond returns. Journal of Financial Economics, 13, 529-546.

Feller, W. (1971). An introduction to probability theory and its applications. Wiley, Vol. 2.

Filipovic, D. (2009). Term-structure models. Springer Finance Textbooks.

Glasserman, P. (2004). Monte Carlo methods in financial engineering. Springer.

Gurrieri, S., Nakabayashi, M., and Wong, T. (2009). Calibration methods of hull-white model. Derivatives eJournal.

Heath, D., Jarrow, R., and Morton, A. (1990). Bond pricing and the term structure of interest rates: A discrete time approximation. Journal of Financial and Quantitative Analysis, 25, 419-440.

Heath, D., Jarrow, R., and Morton, A. (1991). Contingent claims valuation with a random evolution of interest rates. Review of Futures Markets, 9, 54-76.

Heath, D., Jarrow, R., and Morton, A. (1992). Bond pricing and the term structure of interest rates: A new methodology for contingent claims valuation. Econometrica, 60(1), 77-105.

Hillebrand, E. (2003). A mean-reversion theory of stock-market crashes. Economic papers. Retrieved from http://www.bus.lsu.edu/

Ho, T. S. Y., and Lee, S. B. (1986). Term structure movements and pricing interest rate contingent claims. Journal of Finance, 41. doi:10.2307/2328161

Ho, T. S. Y., and Lee, S. B. (2004). The Oxford Guide to financial modeling: Applications for capital markets, corporate finance, risk management and financial institutions. Oxford: Oxford University Press.

Hull, J., and White, A. (1990). Pricing interest-rate derivative securities. The Review of Financial Studies, 3(4), 573-592.

Hull, J., and White, A. (1993). One factor interest rate models and the valuation of interest rate derivative securities. Journal of Financial and Quantitative Analysis, 28(2), June, 235-254.

Hull, J., and White, A. (1996). Using Hull-White interest rate trees. Journal of Derivatives, 3(3), Spring, 26-36.

Hull, J. (2011). Options, futures, and other derivatives. Prentice-Hall.

Jamshidian, F. (1991). Bond and options evaluation in the gaussian interest rate model. Research in Finance, 9, 131-170.

Jamshidian, F. (2010). An overview of interest-rate option models (Working paper), FELAB, University of Twente.

Krishna, P. (2021). Bond Price using Binomial Lattice Model. Retrieved April 25, 2021 from https://www.mathworks.com/matlabcentral/fileexchange/33891-bond-price-using-binomial-latticemodel. MATLAB Central File Exchange.

Li, A., Ritchken, P., and Sankarasubramanian, L. (1995). Lattice Models for pricing American interest rate claims. The Journal of Finance, 50(2), 719-737. 
Longstaff, F. (1989). A non-linear general equilibrium model of the term structure of interest rates. Journal of Financial Economics, 23, 195-224.

Longstaff, F. (1992). Multiple equilibria and term structure models. Journal of Financial Economics, 32, 333-344.

Longstaff, F., and Schwartz, E. (1992). Interest rate volatility and the term structure: A two-factor general equilibrium model. Journal of Finance, 47, 1259-1282.

Maghsoodi, Y. (1996). Solution of the extended CIR Term Structure and Bond Option Valuation. Mathematical Finance, (6), 89-109.

Merton, R. C. (1973). Theory of rational option pricing. Bell Journal of Economics and Management Science, 4, 141-183.

Mishkin, F. S. (1978). Efficient markets theory: Implications for monetary policy. Brookings Papers on Economic Activity, 3, 707-752.

Pesando, J. E. (1979). On the random walk characteristics of short- and long-term interest rates in an efficient market". Journal of Money, Credit and Banking, 11(4), 457-466.

Poterba, J. M., and Summers, L. H. (1988). Mean reversion in stock prices: Evidence and implications. Journal of Financial Economics, 22(1), 27-35.

Ritchken, P., and Sankarasubramanian, L. (1995). Volatility structures of forward rates and the dynamics of the term structure. Mathematical Finance, 5, 55-72.

Rudin, W. (1987). Real \& complex analysis. McGraw-Hill.

Stroock, D. W. (1999). Probability theory: An analytic view. Cambridge: Cambridge University Press. Svoboda, S. (2004). Interest rate modelling. London: Palgrave Macmillan.

Treepongkaruna, S., and Gray, S. (2003). On the robustness of short-term interest rate models. Accounting and Finance, 43(1), 87-121. doi: 10.1111/1467-629x.00084

Vasicek, O. (1977). An equilibrium characterization of the term structure. Journal of Financial Economics, 5(2), 177-188. CiteSeerX 10.1.1.164.447. Retrieved from http://homepages.ulb.ac.be/ $\sim$ cazizieh/Statf508_files/vasicek-1977.pdf

Weisstein, E. W. (n.d.). Wiener Process. Retrieved from http://mathworld.wolfram.com/Wiener Process.html

\section{MODELE KRÓTKOTERMINOWE W RÓWNOWADZE A MODELE BEZ ARBITRAŻU: PRZEGLĄD LITERATURY I PRZYKLADY OBLICZENIOWE}

Streszczenie: W artykule porównano krótkoterminowe modele równowagi $\mathrm{z}$ modelami krótkoterminowymi bez arbitrażu. Opracowanie składa się ze wstępu do przeglądu literatury oraz przykładów estymacji jednoczynnikowych modeli krótkoterminowych, modelu Coxa-Ingersolla-Rossa (CIR) oraz modelu Vasicka. Modele bezarbitrażowe zostały zaprezentowane poprzez model Hulla-White'a (HW), model siatki dwumianowej do wyceny obligacji i modelowania stóp procentowych, model Blacka-Karasińskiego (BK) oraz model Heath-Jarrow-Morton (HJM). Wyniki dowodzą, że nie istnieje jeden model stóp procentowych, który można wykorzystać do wszystkich celów. Modele te porównano pod względem zmienności, procesu rewersji średniej i konwergencji. Wyniki końcowe potwierdzają zależność zmienności od wskaźnika poziomu jako determinanty sukcesu predykcyjnego tych modeli.

Słowa kluczowe: modele równowagi, jednoczynnikowe modele krótkoterminowe, modele bezarbitrażowe, model Vasicka, model Hulla-White'a (HW), model Blacka-Karasinskiego (BK), model Heath-Jarrow-Morton (HJM), model Coxa-Ingersolla-Rossa (CIR). 